
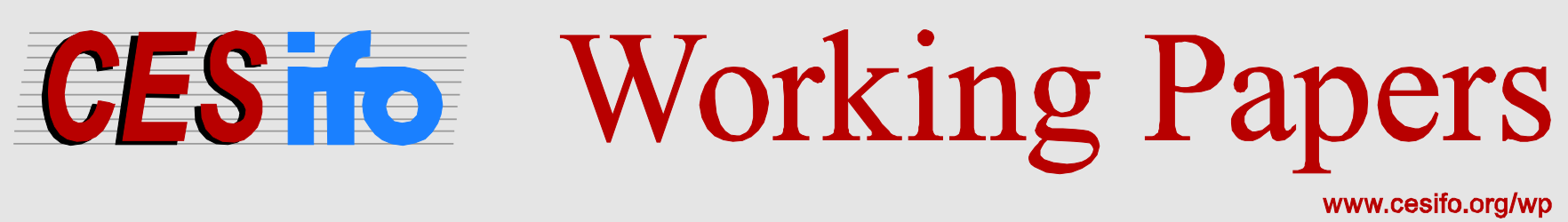

\title{
Inventory Control and Intermediation in Global Supply Chains
}

\author{
Zhan Qu \\ Horst Raff \\ Nicolas Schmitt
}

CESIFO WORKING PAPER NO. 5269

CATEgORY 8: TRAdE POLICY

MARCH 2015

An electronic version of the paper may be downloaded

- from the SSRN website:

- from the RePEc website:

- from the CESifo website:

wWw.SSRN.com

www.RePEc.org

www.CESifo-group.org/wp 


\title{
Inventory Control and Intermediation in Global Supply Chains
}

\begin{abstract}
The paper develops a simple theoretical model of inventory control in global supply chains. It identifies a role for intermediaries in managing inventory, and shows that inserting an intermediary as an additional link in a supply chain is profitable when demand volatility is high. It also provides conditions under which the intermediary handling inventory is located in the exporting versus the importing country. Trade liberalization in the form of less lumpy trade is shown to expand the role of export and import intermediaries but to have potentially negative effects on the volume of international trade and social welfare in the importing country.
\end{abstract}

JEL-Code: F120, F230, L220.

Keywords: international trade, supply chain, inventory, intermediation, lumpy trade.

\author{
Zhan Qu \\ Department of Economics \\ Technical University Dresden \\ Dresden / Germany \\ simon.q@hotmail.com
}

\author{
Horst Raff* \\ Department of Economics \\ Kiel University \\ Germany - 24118 Kiel \\ raff@econ-theory.uni-kiel.de
}

\author{
Nicolas Schmitt \\ Department of Economics \\ Simon Fraser University \\ Canada - Burnaby BC V5A $1 S 6$ \\ schmitt@sfu.ca
}

*corresponding author

March 2015

We would like to thank the Social Sciences and Humanities Research Council of Canada for financial support. 


\section{Introduction}

A large and quickly growing share of international trade is organized in global supply chains that link increasingly fragmented production processes (Baldwin, 2012). Coordinating production along these chains is a complex task that has been studied extensively in the management literature. ${ }^{1}$ This literature has documented that one of the key management problems inherent in the spatial unbundling of production is how to deal with the growing size of inventories. Inventories arise naturally in this context, because production has to occur before consumption (or further processing) and demand is typically uncertain. In fact, using over 500,000 transactions from 211 US public firms, Jain et al. (2014) estimate that a 10\% shift in sourcing from domestic to global suppliers increases average inventory investments by $8.8 \%$.

Economists have not yet given much thought to the issue of inventories in global supply chains, at least as compared to management scientists. For instance, only recently has it been recognized by Alessandria et al. (2014, 2011, 2010a,b) that the size of traded-good inventories matters for economic performance, specifically for the dynamics of international trade flows. ${ }^{2}$ But we still know very little about the economic forces that determine (i) the size of these inventories, (ii) how and by whom inventories are managed, and (iii) what the economic consequences are not only for the volatility of trade, but also for the volume of trade and social welfare.

The purpose of the current paper is to construct a theoretical model of a global supply chain that helps us address these questions. We start with a simple model of a supply chain, in which we endogenize both the size of inventories and the length of the chain in the sense that inventory control may be delegated to an intermediary (as an additional link in the chain). We show that adding an intermediary may reduce inventory and that such a strategy is optimal when final demand is sufficiently volatile. We then add borders by assuming that production takes place in a different country than consumption. This allows us to endogenize the location of the intermediary and thus to consider whether the supply chain includes an export or an import intermediary. Identifying an export intermediary as one allocating goods across destination markets and an import intermediary as one allocating goods across time within a given destination market, we

\footnotetext{
${ }^{1}$ See, for instance, Belavina and Girotra (2012a, b), Biyalogorsky and Koenigsberg (2010), Chen and Gavirneni (2010) and references herein for recent examples. This literature has a very different focus with respect to our paper since it deals mainly with issues linked to management strategies and does not offer insights on international trade issues and social welfare.

${ }^{2}$ Using US industry data, Alessandria et al. (2010b) estimate that an industry that used only imported inputs while exporting all of its output would hold nearly three times as much inventory as an industry that produced only for the domestic market using domestic inputs.
} 
show that an export intermediary is preferred when demands are negatively correlated across destination markets and that an import intermediary is preferred when these demands are positively correlated.

Two examples help to illustrate the role of import and export intermediaries in global supply chains. Consider first the case of O'Neill Inc., a US manufacturer of apparel and accessories for water sports. Because of low production costs, it manufactures its products in Asia resulting in a long lead time for production (3 months), forcing this manufacturer to produce well before the selling season. O'Neill allows for two types of orders from US retailers (Cachon, 2004): one placed well before the selling season (with pre-book discount and delivery guarantee), which means that retailers take possession of the goods, manage inventories and bear the risks associated with demand uncertainty. The other type of order can be made on short notice and is honored provided inventory is available in O'Neill's distribution centre in San Diego. In this case, it is the import-intermediary unit which acts as an importer, controls inventories and bears the risk.

The second example is from the toy market. At the end of the 1990s the US toy market represented nearly half of the world market, and it was dominated by two large firms (Mattel and Hasbro) whose production had largely moved to low-cost Asian countries. Moving production far from consumers was not without loss of flexibility in managing supply as production quantities had to be specified months before the holiday season and there were 'long transit times, custom delays, quota restrictions, and communication barriers [making] managing the supply of products flowing from Asia a challenge' (Johnson, 2001, p. 118). Moreover, the demand for toys is characterized by a heavy concentration of sales in November and December (45\% of US annual sales; Johnson, 2001), a very uncertain success rate as very few toys are typically successful during the Christmas season, and a heavy emphasis on new toys as the most successful ones are rarely so over multiple years. These features suggest that one of the main concerns of the toy firms is to make sure that supply meets demand across different consumer markets, more than to allocate goods through time. This is precisely why Mattel and Hasbro put in place large wholesaling facilities able to divert products 'to Europe or the US depending on inventory needs' (Johnson, p. 120). This example is best associated with the type of export-intermediation activity that we have in mind in this paper.

Whether these intermediaries are affiliates of the manufacturers or independent firms is not critical. Thus, intermediaries could be third-party logistics (3PL) firms (i.e., firms managing inventory storage in their own warehouse) mandated by manufacturers to bridge the gaps between production and consumption and to help control inventories. ${ }^{3}$

\footnotetext{
${ }^{3}$ Industry Canada (2008) reports that third-party logistics (3PL) firms play an essential role in global supply chains involving Canadian firms. According to the report (see
} 
What advantages do intermediaries have in controlling inventory relative to downstream firms, say retailers or downstream producers, who in principle could also hold inventory? Following the market microstructure literature (Spulber, 1999), our theory of intermediation is built on the assumption that intermediaries possess market power. ${ }^{4}$ In fact, we show that market power creates a role for intermediaries in controlling inventory even if they do not possess a superior technology relative to competitive downstream firms. The economic mechanism behind this is simple. An intermediary with market power holds inventory to equalize today's marginal revenue with tomorrow's expected marginal revenue, whereas competitive downstream firms hold inventory so as to equalize today's price with tomorrow's expected price. This implies that inventories are smaller and trade volatility is reduced when inventory is controlled by an intermediary, which also explains why intermediaries are especially useful when final demand is very volatile. Simply put, the intermediary's incentives to control inventory are better aligned with the interests of the manufacturer because the intermediary intertemporally segments sales periods whereas, in its absence, competitive downstream firms integrate them. The intermediary's advantage outweighs the resource cost of intermediation in volatile markets where inventories tend to be big. This basic advantage of intermediaries in controlling inventory carries over to the other environments we examine, namely to the case where the intermediary may be located in the exporting or the importing country.

We then expand the model by adding an international trade friction by assuming that trade may be lumpy in the sense that any shipment across borders needs to cover more than one sales period. ${ }^{5}$ The fact that lumpiness

background material to Figure 9), the number of medium and large 3PL firms in Canada has increased from 298 firms in 1998 to 443 firms in 2007, an increase of nearly 50\%. At the same time there was considerable consolidation in the industry with the number of small firms falling from 1586 to 1446 . Thus the total number of 3PL firms was nearly stable, but given the shift toward bigger firms the importance of 3PL activities has certainly increased. World Bank (2014) reports that 3PL firms had an estimated global market of $\$ 677$ billion in 2012 ( $\$ 236$ billion in Asia, $\$ 170$ billion in the US and $\$ 156$ billion in Europe).

${ }^{4}$ Spulber (1999, p. xvii) argues that any market microstructure theory requires intermediaries to have at least some market power so that they can set prices and balance supply and demand across time. Providing "immediacy services", that is, standing ready to buy and sell goods at different points in time is seen as a key role of intermediaries.

${ }^{5}$ The World Bank's Doing Business project (see www.doingbusiness.org/) finds that the time necessary to complete documentation, custom, inspections, port and terminal handling for a container transported by ocean shipping adds an average delivery lag of 9-11 days for exports from and imports to high income OECD countries and 30-38 days for exports from and imports to South Asian or Sub-Sahara African countries. See also Hummels and Schaur (2013), Crista, et al. (2013). The Great Recession has led financiallystrapped ocean carriers to cut fuel costs by reducing vessel speeds from 25 to 22 knots, which adds up to three days to the 11-12 days voyage between Asia and North America (Bonney and Leach, 2010). Interestingly, the protracted 2014 West Coast longshore contract negotiations have led US retailers to import back-to-school and holiday merchandise 
is an additional reason for holding inventory and that it affects the dynamics of international trade is best seen through the example of a US steel wholesaler. This wholesaler purchases products both at home and abroad, with delivery of foreign steel products taking up to twelve weeks from the date orders are placed (Hall and Rust, 2000). ${ }^{6}$ Table 1 contrasts the average weight and average interval of domestic and foreign orders for 469 products that have both domestic and foreign purchase transactions. The relative lumpiness of foreign transactions shows up in the average weight of foreign orders, which is nearly twice as big as that of domestic ones, and in the average interval between orders, which is on average $19 \%$ longer for foreign than for domestic transactions. ${ }^{7}$ Table 1 also shows that the coefficients of variation $(\mathrm{CV})$ associated with foreign transactions are lower for both weight and transaction interval than they are for domestic transactions. Hence, whether for weight or interval, foreign transactions exhibit more regularity, less randomness around the mean than domestic transactions even for the same set of products. ${ }^{8}$

Table 1: US Steel Wholesaler's Purchasing Transactions Domestic Foreign

$\begin{array}{lll}\text { \# transactions } & 7,449 & 4,257 \\ \text { Average weight } & 62,427 & 119,282 \\ \text { Average interval (days) } & 203 & 241 \\ \text { CV weight } & 1.97 & 1.59 \\ \text { CV interval } & 1.39 & 1.26\end{array}$

We first show that the benefit of intermediation within a supply chain may be smaller when trade is lumpy, and second that lumpiness increases the relative attractiveness of an import intermediary compared to an export intermediary. We also prove that the welfare effects of intermediation may depend on the lumpiness of trade. In particular, we argue that trade liberalization in the form of less lumpy trade may not only lead to more intermediation but also to lower social welfare. The reason is not just that intermediation involves a resource cost. Rather, by improving the allocation of goods across time, intermediaries also allow the manufacturer to better

much earlier than usual ahead of any potential problems (Lavigne, 2014).

${ }^{6}$ For each purchase transaction, we know the unit price, the number of units ordered, the weight per order, a code indicating whether sourcing is domestic or foreign, the amount paid and the delivery date. We thank George Hall and John Rust for making the data available to us. See Alessandria et al. (2010a) for additional details on this data set.

${ }^{7}$ The average interval is an average of averages. Specifically we treat each set of transactions separately, we then compute the average interval at the individual product level before averaging these averages. Note that we disregard same date transactions at the product level. The results are qualitatively the same if these transactions are included.

${ }^{8} \mathrm{~A}$ reason may be that the wholesaler regularly stocks foreign sourced goods, looking to domestic sources only when demand unexpectedly exceeds the inventory of foreign sourced products (see for instance Allon and van Mieghem, 2010). 
extract consumer surplus, and in the process sales may fall. When trade is lumpy this potentially negative effect on welfare is less likely to occur, which under certain conditions is enough to guarantee welfare gains from intermediation.

The paper can be seen as contributing to several strands of the literature. Our paper is linked to the literature on intermediation in international trade, particularly to the articles investigating direct versus indirect exports (Ahn, Khandelwal and Wei, 2011; Akerman, 2011; Blum, Claro and Horstmann, 2012; Crozet, Lalanne and Poncet, 2013; Felbermayr and Jung, 2011; Krautheim, 2013; Schroeder, Trabold and Trueswetter, 2005, among others). ${ }^{9}$ To this literature we bring inventory considerations and endogenous import and export intermediation. Indeed, to our knowledge, our paper is the first attempting to distinguish between export and import intermediaries.

But our paper is more closely linked to two other literatures: the one on global supply chains, and the literature on inventories and the dynamics of international trade. With respect to the first literature (see, for instance, Baldwin and Venables, 2013; Costinot et al., 2013; Fally and Hillberry, 2014), the main contribution of our paper is to endogenize the number of links within a chain and to show that inventories are smaller in a longer chain than they are in a shorter chain. This contrasts with articles (see for instance, Altomonte et al., 2013) linking inventory volumes and the ownership structure of a supply chain. Their argument rests on the idea that a common flow of information about the state of final demand allows for quicker adjustments of orders and for lower inventories at each link along a supply chain within a multinational company and its affiliates compared to a chain in which firms deal at arm's length and face the so-called 'bullwhip effect' (Forrester, 1961). Ownership considerations play no role in our model; instead it is the length of the supply chain that matters for inventory volumes because of the advantage brought by intermediation. With respect to the literature on inventories and the dynamics of international trade (Alessandria, Kaboski and Midrigan, 2014, 2011, 2010a,b; Hornok and Koren, 2014; Kropf and Sauré, 2013), our main contribution is to show that the implications for trade dynamics and welfare are not the same depending on who engages in international trade. Indeed it is precisely because intermediaries' main role in our model is to control inventories that the dynamics of trade and social welfare are different with respect those associated with no intermediation.

The paper is organized as follows. In Section 2 we present the model and solve for the equilibrium without intermediation. In Section 3, we add intermediation and establish when it benefits the supply chain. We then

\footnotetext{
${ }^{9}$ See also Antras and Costinot (2011) for trade intermediaries engaged in search and matching, Feenstra and Hanson (2004) for the role of Hong Kong intermediaries, and Bernard et al. $(2010,2011)$ for the importance of intermediation in US trade and in Italy.
} 
introduce borders and international trade in Section 4. This allows us to establish the relative merit of export and import intermediation. In Section 5 we examine how the equilibrium of this simple model changes when, in addition to a production lag, we have a trade lag and lumpy trade. In particular, we show how trade lumpiness affects further the relative merits of import and export intermediaries and the benefit of intermediation itself. In Section 6 we consider a more general demand function to identify sufficient conditions under which intermediation may raise or lower the volume of trade and social welfare depending on trade lumpiness. Section 7 contains conclusions, and the Appendix collects the proofs of our results.

\section{A Simple Model of Inventory Control}

Consider an upstream producer (hereafter, called the manufacturer) who supplies its product to a continuum of perfectly competitive downstream firms. Downstream firms - either manufacturers purchasing an intermediate good or retailers purchasing a final good - in turn sell to consumers. Final demand is random and all market participants are risk neutral.

There are two periods, $t=1,2$. Orders are placed and production takes place at the beginning of each period before demand is known. Consumption occurs at the end of each period. A production lag thus occurs within each period. ${ }^{10}$ In this setting downstream firms may hold inventory, i.e., carry over unsold goods from period 1 for sale in period 2 .

Demand at time $t=1,2$ is given by the linear inverse demand function: $p_{t}=A-s_{t}+\varepsilon_{t}$, where $s_{t}$ denotes final sales and $p_{t}$ is the consumer price. The random variables $\varepsilon_{t} \in[-d, d]$ are intertemporally independent and uniformly distributed with density $\frac{1}{2 d}$.

Our assumptions about the production and distribution technologies are as simple as possible. The manufacturer incurs a constant unit cost of production $c$. The marginal production cost of downstream firms is normalized to zero, as is the trade cost and the cost of holding inventory. There is no discounting. We make the additional assumption that the demand shock is not too big:

$$
d \leq \min \left\{\frac{2\left(c+c_{w}\right)}{3}, \frac{A-c}{4}, \frac{A-\left(c+c_{w}\right)}{2}\right\}
$$

(where $c_{w}$ is a per-unit cost of intermediation that we will use in the next section). Assumption (A1) rules out situations in which demand is (i) so high that there are stockouts in equilibrium, (ii) so low that when downstream firms sell goods at the end of period 2 the consumer price drops to zero, and

\footnotetext{
${ }^{10}$ See Evans and Harrigan (2005), and Raff and Schmitt (2007) for related models applied to different issues.
} 
(iii) so low in period 1 that shipments in period 2 are zero. ${ }^{11}$

Next we describe the timing of events. At the beginning of period 1 the manufacturer announces a producer price $P_{1}$. Downstream firms order and take possession of $q_{1}$ units of goods before demand in period 1 is known; then period-one demand is revealed and the downstream firms sell $s_{1} \leq q_{1}$ in period 1 , holding unsold units as inventory for period 2 . In period 2 , the manufacturer sets producer price $P_{2}$, and downstream firms order quantity $q_{2}$, again before period-two demand is known. Demand in period 2 is then revealed and downstream firms sell $s_{2} \leq q_{2}+\left(q_{1}-s_{1}\right)$.

To derive the equilibrium, we first consider period 2. After observing demand downstream firms sell all of the products on hand, and hence $s_{2}=$ $q_{2}+q_{1}-s_{1}$, because they have already paid for these goods and, by (A1), the consumer price is positive. Downstream firms order goods at producer price $P_{2}$ before the demand shock is realized. Perfect competition among downstream firms implies that they order goods until expected profits are zero, so that $q_{2}$ satisfies:

$$
E_{2}\left(A-q_{2}-q_{1}+s_{1}+\varepsilon_{2}\right)\left(q_{2}+q_{1}-s_{1}\right)-P_{2} q_{2}=0 .
$$

The manufacturer chooses $P_{2}$, respectively $q_{2}$, that maximizes its period-2 expected profit $E_{2}\left(\pi_{2}\right)=P_{2} q_{2}-c q_{2}$. Using (1) to substitute for $P_{2} q_{2}$, it is easily shown that this expected profit is maximized when downstream firms order an amount $q_{2}=\frac{A-c}{2}-\left(q_{1}-s_{1}\right)$, implying sales in period 2 of $s_{2}=\frac{A-c}{2}$. The expected consumer price in period 2 is thus equal to $E_{2}\left(p_{2}\right)=\frac{A+c}{2}$.

Notice that in period 1 , after $\varepsilon_{1}$ has been revealed, the downstream firms decide how much to sell now and how much inventory to keep for period 2. Being price takers they sell the quantity that equalizes the consumer price in period 1 and the expected consumer price in period 2, holding any surplus as inventory for period $2 .{ }^{12}$ The consumer price in period 1 thus satisfies $p_{1}=A-s_{1}+\varepsilon_{1}=\frac{A+c}{2}$, and therefore first-period sales are equal to $s_{1}=\frac{A-c}{2}+\varepsilon_{1}$.

These first-period sales can only be realized if $s_{1} \leq q_{1}$ so that there are no stockouts. Given that any unsold goods can be held in inventory at no cost, it is optimal to set producer price $P_{1}$ so that downstream firms order $q_{1}=\frac{A-c}{2}+d$ and stockouts are avoided for any value of $\varepsilon_{1}$. In period 2 the quantity shipped is then equal to $q_{2}=s_{2}-\left(q_{1}-s_{1}\right)=\frac{A-c}{2}-\left(d-\varepsilon_{1}\right)$. Here $\left(d-\varepsilon_{1}\right)$ represents the level of inventory held by the downstream firms. Thus a demand shock in period $1, \varepsilon_{1}$, leads to a change in inventory, and the latter affects the quantity shipped in period $2 .{ }^{13}$ Obviously the greater

\footnotetext{
${ }^{11}$ We explain at the end of the next section why assumption (A1) and the assumption of no inventory cost both bias our results against adding an intermediary in the value chain. For now suffice it to say that these assumptions leave our results qualitatively unchanged.

${ }^{12}$ Note that, if all the other competitive firms behave in this way, the best response for any given individual competitive firm is also to follow this strategy.

${ }^{13} \mathrm{It}$ is easy to see that this argument does not depend on having only a two-period
} 
is the variance of demand, the greater is the variance of shipments, which is equal to $\operatorname{Var}\left(q_{2}\right)=d^{2} / 3$.

Finally we compute the manufacturer's expected total profit. The total quantity ordered over both periods is $q_{1}+q_{2}=A-c+\varepsilon_{1}$. Since in equilibrium downstream firms make zero expected profit, their expected total revenue has to equal their expected total spending on goods:

$$
\int_{-d}^{d} \frac{A+c}{2}\left(A-c+\varepsilon_{1}\right) \frac{1}{2 d} d \varepsilon_{1}=P_{1} q_{1}+P_{2} q_{2} .
$$

Using (2) the manufacturer's expected total profit, $E(\pi)=P_{1} q_{1}+P_{2} q_{2}-$ $E\left[c\left(q_{1}+q_{2}\right)\right]$, is

$$
E(\pi)=\frac{(A-c)^{2}}{2}
$$

\section{The Role of Intermediaries in Inventory Control}

Suppose now that the manufacturer uses an intermediary to control inventory and thus adds a link in the supply chain. More precisely, the intermediary takes over from the downstream firms the inventory holding across periods; the downstream firms simply sell in each period whatever they buy from the intermediary in that period. For the intermediary, just like for downstream firms, the cost of holding inventory is zero. However, intermediation involves a resource $\operatorname{cost} c_{w}$ per-unit shipped. The manufacturer sets a two-part tariff for the intermediary, consisting of the producer price $P_{t}$ and a fixed payment (or transfer) $T_{t}$ for $t=1,2$. The intermediary in turn charges a wholesale price $w_{t}{ }^{14}$

The timing of the game is now as follows: at the beginning of period 1 the manufacturer sets a two-part tariff $\left(P_{1}, T_{1}\right)$, the intermediary orders and takes possession of quantity $q_{1}$. Demand in period 1 is then revealed, the intermediary chooses wholesale price $w_{1}$, downstream firms purchase from the intermediary and sell to consumers a quantity $s_{1} \leq q_{1}$. In period 2 the intermediary reorders a quantity $q_{2}$ at the two-part tariff $\left(P_{2}, T_{2}\right)$. Then demand in period 2 is revealed, the intermediary sets wholesale price $w_{2}$, downstream firms order and sell $s_{2} \leq q_{2}+\left(q_{1}-s_{1}\right)$.

The equilibrium can be determined as follows. In period 2 after demand has been revealed and given a wholesale price $w_{2}$, downstream firms

model. Even in a setting with more periods downstream firms have an incentive to hold inventory so as to equalize prices across time. Thus a demand shock in one period will affect trade in the subsequent period in the same way.

${ }^{14}$ The intermediary cannot demand a fixed payment from the downstream firms, since they earn zero profit in equilibrium. The two-part tariff set by the manufacturer implies that, like in the case without intermediary, the entire expected profit generated by the value chain goes to the manufacturer. The manufacturer also has no incentive to use more than one intermediary. 
order and then sell an amount $s_{2}$ that satisfies the zero-profit condition $\left(A-s_{2}+\varepsilon_{2}\right) s_{2}-w_{2} s_{2}=0$. Thus, the intermediary's expected period-two revenue is $E_{2}\left[\left(A-s_{2}+\varepsilon_{2}\right) s_{2}\right]=\left(A-s_{2}\right) s_{2}$, and the expected marginal revenue is $E\left(M R_{2}\right)=A-2 s_{2}$.

Similarly, in period 1 , after $\varepsilon_{1}$ has been revealed, the intermediary sets a wholesale price $w_{1}$ and downstream firms purchase and sell quantity $s_{1}$, such that $\left(A-s_{1}+\varepsilon_{1}\right) s_{1}-w_{1} s_{1}=0$. The intermediary's revenue hence is equal to $\left(A-s_{1}+\varepsilon_{1}\right) s_{1}$, and the corresponding marginal revenue is $M R_{1}=$ $A-2 s_{1}+\varepsilon_{1}$.

To determine the intermediary's optimal wholesale prices, respectively sales to downstream firms in each period, assume that the manufacturer charges the same producer price in both periods, $P_{1}=P_{2}=P$ (we explain below that it is indeed what the manufacturer chooses to do), so that the intermediary's marginal cost is equal to $P+c_{w}$. To maximize its profit the intermediary sells quantities such that $M R_{1}=E\left(M R_{2}\right)=P+c_{w}$. It follows that $s_{1}=\left(A-\left(P+c_{w}\right)+\varepsilon_{1}\right) / 2$ and $s_{2}=\left(A-\left(P+c_{w}\right)\right) / 2$.

The intermediary can avoid a stockout in period 1 by ordering a quantity $q_{1}=\left(A-\left(P+c_{w}\right)+d\right) / 2$, which guarantees that $s_{1} \leq q_{1}$ for all $\varepsilon_{1}$. This is indeed optimal given a zero cost of holding inventory. In period 2 the intermediary thus orders $q_{2}=s_{2}-\left(q_{1}-s_{1}\right)=\frac{A-\left(P+c_{w}\right)}{2}-\frac{1}{2}\left(d-\varepsilon_{1}\right)$.

The level of inventory held by the intermediary, $\left(d-\varepsilon_{1}\right) / 2$, is thus only half as large as the inventory that would be held by downstream firms in the absence of an intermediary. The variance of shipments in period 2 with intermediation is $\operatorname{Var}\left(q_{2}\right)=d^{2} / 12$ and thus only a quarter as high as the variance in the absence of intermediation. This proves our first result:

Proposition 1 Inventory is smaller and shipments are less volatile if the inventory is controlled by an intermediary.

This result is due to the fact that an intermediary with market power faces different incentives to hold inventory than competitive downstream firms. Recall from the previous section that downstream firms, after observing demand in period 1 sell the quantity that equalizes the first-period consumer price with the expected second-period consumer price. When demand turns out to be low in period 1, this implies that downstream firms sell very little and thus hold a large inventory; but when first-period demand is high, downstream firms sell a lot and hold very little inventory. In fact, when downstream firms control the inventory, first-period sales differ from expected second-period sales by the amount of the demand shock: $s_{1}-s_{2}=\varepsilon_{1}$. By contrast, when an intermediary controls the inventory, sales in period 1 differ from expected sales in period 2 by only half the amount of the shock: $s_{1}-s_{2}=\frac{1}{2} \varepsilon_{1}$. The reason is that after observing demand in period 1 the intermediary chooses the wholesale price so as to equalize the marginal revenue in period 1 and the expected marginal revenue in period 2 (which 
is equal to the intermediary's marginal cost). This implies that, compared to the case without intermediation, the intermediary induces downstream firms to sell more when demand is low and less when demand is high, which reduces the volatility of shipments in period 2 . Since sales in high-demand states are smaller in the case of intermediation, the quantity that has to be ordered to prevent a stockout in period 1 is also smaller in this case, which explains why an intermediary holds less inventory than downstream firms.

Another way to understand why the manufacturer values the intermediary is to recognize that if $M R_{1}=E\left(M R_{2}\right)$, then $p_{1} \neq E\left(p_{2}\right)$. Thus the intermediary's strategy amounts to segmenting the two sales periods (intertemporal market segmentation). In the absence of intermediation, by equating $p_{1}$ and $E\left(p_{2}\right)$, the downstream firms in effect integrate markets across periods (intertemporal market integration).

The benefit an intermediary brings to the supply chain evidently stems from the fact that its incentive to hold inventory is better aligned with the interests of the manufacturer than the incentives of downstream firms. This benefit has to be traded off against the cost of intermediation, which simply is the resource cost of $c_{w}$ per unit.

To show this trade-off formally notice that the total expected profit of the intermediary for a given producer price $P$ and transfer $T$ is given by:

$$
\begin{gathered}
\underbrace{\int_{-d}^{d}\left(A-\frac{A-\left(P+c_{w}\right)+\varepsilon_{1}}{2}+\varepsilon_{1}-\left(P+c_{w}\right)\right)\left(\frac{A-\left(P+c_{w}\right)+\varepsilon_{1}}{2}\right) \frac{1}{2 d} d \varepsilon_{1}}_{\text {expected profit in } \mathrm{t}=1} \\
+\underbrace{\left(A-\frac{A-\left(P+c_{w}\right)}{2}-\left(P+c_{w}\right)\right)\left(\frac{A-\left(P+c_{w}\right)}{2}\right)}_{\text {expected profit in } \mathrm{t}=2}-T .
\end{gathered}
$$

After evaluating the integral this simplifies to $\frac{\left[A-\left(P+c_{w}\right)\right]^{2}}{2}+\frac{d^{2}}{12}-T$. The optimal two-part tariff has the manufacturer set $P=c$ so as to avoid double marginalization and set $T$ so as to extract the intermediary's entire expected profit. It follows that the manufacturer's expected profit when trading with the help of an intermediary is then given by

$$
E\left(\pi^{i n t}\right)=\frac{\left[A-\left(c+c_{w}\right)\right]^{2}}{2}+\frac{d^{2}}{12} .
$$

Comparing (4) with (3) we may state the following result:

Proposition 2 The manufacturer uses an intermediary to control inventory if the variance of demand (and thus d) is sufficiently large.

At this point it is useful to briefly consider how relaxing two simplifying assumptions would influence our results. Making inventory costly to hold 
would introduce a trade-off between reducing the possibility of a stockout by ordering a larger quantity in period 1 and limiting the cost of holding inventory by keeping the first-period order small. This trade-off would evidently differ between downstream firms and the intermediary, as downstream firm face more volatile sales and thus require a larger order to avoid a stockout. The benefit of using an intermediary would thus be even bigger in the case of inventory costs.

Relaxing (A1) would also not fundamentally alter our results. First, consider allowing for the possibility of stockouts. This would create interesting economic trade-offs only in combination with costly inventory. As explained above, an intermediary reduces sales volatility and thus the threat of a stockout, making the use of an intermediary a more advantageous choice. Second, allowing demand shocks to be so big that the consumer price may drop to zero in period 2 when downstream firms dump their goods on the market would also create an additional incentive to use an intermediary. The reason is that downstream firms facing a threat of such "destructive competition" tend to order less than an intermediary who can always guarantee a positive consumer price in period $2 .{ }^{15}$

In the following sections we consider two extensions that add an international dimension to our analysis. We first consider a case where the manufacturer ships goods to more than one market. Combined with (implicit) trade costs, this raises the question of where the inventory should be held. Second, we consider the case of lumpy trade and investigate the changing role of intermediaries as trade becomes less lumpy.

\section{Export versus Import Intermediaries}

In the previous section we found out when it pays the manufacturer to add a link in the supply chain by delegating inventory control to an intermediary. We now introduce a border between the manufacturer and consumers implying that this intermediary can be located either in the exporting or in the importing country. The purpose of this section is thus to understand the circumstances under which the manufacturer uses either an export or an import intermediary.

In order to make this choice interesting, we introduce two new elements. First, we consider more than one consumption market. Specifically, we assume that the manufacturer ultimately supplies competitive downstream firms in two identical countries, denoted $\alpha$ and $\beta$. Second, we assign separate roles to the export and to the import intermediaries. Specifically, we let

\footnotetext{
${ }^{15}$ See Raff and Schmitt (2007) for a formal analysis of destructive competition under similar circumstances. Also note that the case, also ruled out by (A1), where demand in period 1 is so small that there are no shipments in period 2 is rather similar to the case of lumpy trade discussed below.
} 
an export intermediary allocate goods across export destinations, and an import intermediary allocate goods across time within a given destination market. An export intermediary thus is a firm that takes possession of goods in the country of origin and allocates them across the two countries but not across periods. Hence, this export intermediary does not hold any inventory. By contrast an import intermediary is a firm that takes possession of goods in the country of destination. There it may allocate goods across periods by holding inventory. But it does not allocate goods across countries. ${ }^{16}$

We make the following additional adjustments to the model and to the notation. Demand in country $i=\alpha, \beta$ at time $t=1,2$ is given by the linear inverse demand function: $p_{i t}=A-s_{i t}+\varepsilon_{i t}$, where $s_{i t}$ denotes final sales and $p_{i t}$ is the consumer price. The random variables $\varepsilon_{i t} \in[-d, d]$ are intertemporally independent, but in each period may be correlated across the two countries. In particular, for $t=1,2$, let $f\left(\varepsilon_{\alpha t}, \varepsilon_{\beta t}\right)$ denote the joint density function and assume that the marginal densities are uniform so that $f_{\alpha}\left(\varepsilon_{\alpha t}\right)=\int_{-d}^{d} f\left(\varepsilon_{\alpha t}, \varepsilon_{\beta t}\right) d \varepsilon_{\alpha t} \equiv \frac{1}{2 d}$ and $f_{\beta}\left(\varepsilon_{\beta t}\right)=\int_{-d}^{d} f\left(\varepsilon_{\alpha t}, \varepsilon_{\beta t}\right) d \varepsilon_{\beta t} \equiv$ $\frac{1}{2 d}$. Furthermore, suppose that $f_{t}\left(\varepsilon_{\alpha t}, \varepsilon_{\beta t}\right) \neq f_{\alpha}\left(\varepsilon_{\alpha t}\right) f_{\beta}\left(\varepsilon_{\beta t}\right)$, and let the correlation coefficient between $\varepsilon_{\alpha t}$ and $\varepsilon_{\beta t}$ be $\rho$ for $t=1,2$.

It should be obvious from the above that our import intermediary is identical to the intermediary analyzed in the previous section. All we have done it to locate one in each destination market. We therefore concentrate on analyzing the case of the export intermediary. ${ }^{17}$

The timing in the case of an export intermediary is as follows. In period 1 after observing the two-part tariff $\left(P_{1}, T_{1}\right)$ the export intermediary orders and takes possession of quantity $q_{1}$. After demand has been revealed, it sets wholesale prices $w_{\alpha 1}$ and $w_{\beta 1}$ to allocate $q_{1}$ across countries $\alpha$ and $\beta$. Downstream firms then sell output to consumers, where it has to be the case that $s_{\alpha 1}+s_{\beta 1} \leq q_{1}$. In period 2 , the export intermediary faces producer tariff $\left(P_{2}, T_{2}\right)$, reorders quantity $q_{2}$ and resells it to downstream firms at wholesale prices $w_{\alpha 2}$ and $w_{\beta 2}$ so that $s_{\alpha 2}+s_{\beta 2} \leq q_{2}$. Analyzing this game is thus equivalent to considering twice a one-period case. So we can omit the time subscript $t$.

Consider an export intermediary who has taken delivery of a quantity of goods, $q$, and sets wholesale prices so as to allocate this quantity among

\footnotetext{
${ }^{16}$ In other words, it is the ability of allocating goods across time that primarily characterizes our import intermediary. It does not mean that an import intermediary could not also spatially allocate goods but that this role is secondary and thus ignored here. The same is true for our export intermediary: the spatial allocation of goods is seen as the main role and the allocation across time is secondary, and thus ignored in our analysis.

${ }^{17}$ Recall that with a two-part tariff the manufacturer has no incentive to use more than one export intermediary and, in the case of import intermediaries, more than one in each destination country. We also assume that shipping costs are sufficiently high that while goods can be shipped to each destination country, it never pays to re-export them to the other destination country. That is, we assume away any parallel trade. See Raff and Schmitt (2007) for a model in which downstream firms engage in parallel trade.
} 
the two countries such that $s_{\alpha}+s_{\beta}=q$. Facing a wholesale price $w_{i}$ competitive downstream firms in country $i=\alpha, \beta$ order and sell output until profit is equal to zero: $\left(A-s_{i}+\varepsilon_{i}\right) s_{i}-w_{i} s_{i}=0$. The intermediary earns a total revenue in the two countries of $\left(A-s_{\alpha}+\varepsilon_{\alpha}\right) s_{\alpha}+\left(A-s_{\beta}+\varepsilon_{\beta}\right) s_{\beta}$. To maximize this revenue, the wholesale prices should be set so as to equalize marginal revenues across the two countries: $A-2 s_{\alpha}+\varepsilon_{\alpha}=A-2 s_{\beta}+\varepsilon_{\beta}$. Together with the condition $s_{\alpha}+s_{\beta}=q$, this implies $s_{\alpha}=\frac{2 q+\left(\varepsilon_{\alpha}-\varepsilon_{\beta}\right)}{4}$ and $s_{\beta}=\frac{2 q-\left(\varepsilon_{\alpha}-\varepsilon_{\beta}\right)}{4}$. That is, the export intermediary is able to reallocate goods so that the market with the higher realized demand receives a proportionately larger quantity.

How this may benefit the manufacturer is shown explicitly in the Appendix, where we derive the manufacturer's expected profit per destination market when exporting through an export intermediary:

$$
E\left(\pi^{e x}\right)=\frac{\left[A-\left(c+c_{w}\right)\right]^{2}}{2}+\frac{d^{2}}{12}(1-\rho) .
$$

Comparing (5) with (4) yields the following result:

Proposition 3 Suppose trade is intermediated. Then import intermediaries are used if demands are positively correlated across countries $(\rho>0)$. An export intermediary is used if demands are negatively correlated across countries $(\rho<0)$.

Even if channeling trade through an intermediary is costly, it is still optimal for a manufacturer to use an import or an export intermediary when the demand volatility is sufficiently high. This is because an intermediary allows for a better spatial or intertemporal allocation of goods from the manufacturer's point of view.

\section{Trade Lumpiness and Intermediation}

In addition to the production lag there may also be a time lag involved in shipping goods between the country of origin and destination countries $\alpha$ and $\beta$. A sufficiently long time lag makes trade lumpy providing an additional reason for keeping inventory. We define lumpy trade as a situation, in which goods may only be shipped at the beginning of period 1 for consumption in periods 1 and 2 . The quantity that has been ordered in period 1 for sale in country $i$, say $Q_{i}$, has to last for two periods so that the downstream firms' sales in the two periods satisfy $s_{i 1}+s_{i 2} \leq Q_{i}$.

Consider first the case where inventory is controlled by downstream firms. ${ }^{18}$ In this scenario the manufacturer sets a producer price $P_{i}$, then

\footnotetext{
${ }^{18}$ Detailed derivations of the results for the case of no intermediation, trade through import intermediaries, and trade through an export intermediary are provided in the Appendix.
} 
downstream firms in each country $i=\alpha, \beta$ order quantity $Q_{i}$. In period 1 , after the demand shock $\varepsilon_{i 1}$ has been resolved, downstream firms decide how much to sell in period 1 , and the leftover is sold in period 2. We find that trade lumpiness has no effect on the expected total shipment to a country, $(A-c)$, nor on the manufacturer's expected profit, which is still given by (3). The degree of lumpiness simply does not affect the manufacturer's producer price so that downstream firms order the same expected quantity.

Next consider the case of an import intermediary. This intermediary adjusts the wholesale price in period 1 after observing $\varepsilon_{1}$ in order to allocate output across periods until the marginal revenue in period 1 is equal to expected marginal revenue in period 2. The manufacturer's total expected profit from exporting to a country via an import intermediary is

$$
E\left(\pi_{i m p}^{l}\right)=\frac{\left[A-\left(c+c_{w}\right)\right]^{2}}{2}+\frac{d^{2}}{24} .
$$

Like in the case of non-lumpy trade, it pays to introduce an import intermediary when the variance of demand is sufficiently large relative to the cost of intermediation. Notice, however, from (6) and (4) that the benefit of an import intermediary is now smaller than in the case of non-lumpy trade. This is, of course, due to the fact that the intermediary cannot reorder goods in period 2. More precisely, when goods can be reordered in period 2, the import intermediary, after observing $\varepsilon_{1}$, not only equates marginal revenue in period 1 with expected marginal revenue in period 2; it also knows that it will be able reorder goods to make sure that the expected marginal revenue in period 2 equals marginal cost. This ability to optimally adjust sales in period 2 is absent when goods are ordered only once at the beginning of period 1.

Finally consider trade intermediated by an export intermediary. The optimal strategy of the export intermediary after observing the demand shocks $\varepsilon_{\alpha 1}$ and $\varepsilon_{\beta 1}$ is to set wholesale prices so that the competitive firms order the quantities $Q_{\alpha}$ and $Q_{\beta}$ that equalize marginal revenues across the two countries. The expected profit of the manufacturer from exporting to a given country is

$$
E\left(\pi_{\text {exp }}^{l}\right)=\frac{\left[A-\left(c+c_{w}\right)\right]^{2}}{2}+\frac{d^{2}}{48}(1-\rho) .
$$

Like in the case of non-lumpy trade, trading through an export intermediary is profitable if the variance of demand is large relative to the resource cost of intermediation, provided demands in the two countries are not perfectly correlated. But we observe from (5) and (7) that the advantage of using an export wholesaler is smaller than in the case of non-lumpy trade. The reason for this is that the intermediary in the case of lumpy trade has only one opportunity to allocate inventory across countries. Once the 
export intermediary has completed this allocation, downstream firms in the two countries face the "wrong" incentives - wrong from the point of view of the manufacturer and of the intermediary - to allocate inventory across time, namely by selling until the first-period price is equal to the expected second-period price. This intertemporal "misallocation" of inventory does not take place when there is non-lumpy trade.

It is immediate from the above discussion that trade lumpiness changes the relative benefit of using import compared to export intermediaries, making import intermediaries more attractive. We may therefore state:

Proposition 4 When trade is lumpy the manufacturer strictly prefers import intermediaries to an export intermediary unless demand shocks in the two countries are perfectly negatively correlated $(\rho=-1)$.

This is an interesting result because it indicates that lumpy trade penalizes more an export than an import intermediary. It is the case because, unlike an import intermediary, the export intermediary loses control of the intertemporal allocation of products once they have been shipped.

The analysis also implies that the use of intermediaries and thus the length of supply chains depends on trade lumpiness. The benefit of using an import or export intermediary is lower in the case of lumpy trade than with non-lumpy trade. That is, they are only used for higher levels of the variance of demand. The consequence of this is immediate:

Proposition 5 As trade becomes less lumpy the likelihood that trade is intermediated and that it is intermediated by an export rather than an import intermediary rises.

In other words, as trade becomes less lumpy inventories are more likely to be managed by intermediaries rather than by downstream firms. The reason is clear: an intermediary, whether on the import or on the export side, is less constrained with non-lumpy than with lumpy trade and is thus more useful to a manufacturer as an additional link within the supply chain. In addition, the advantage of an export intermediary rises compared to that of an import intermediary, as there are increased opportunities to allocate goods across countries.

There is indeed some evidence that trade lumpiness has decreased over time. Table 2 shows in particular that the time and the cost of ocean shipments associated with import procedures has fallen over the last eight years irrespective of the country group. ${ }^{19}$ Because time and cost are measured by

\footnotetext{
${ }^{19}$ Based on World Bank's Doing Business data measuring country-specific time and costs (excluding tariffs) associated with official export and import procedures (thus excluding the time and cost of transportation) of a standard product traveling in a dry-cargo, 20foot, full container load weighing 10 tons with a value of $\$ 20,000$. We used (World Bank) GDP deflators per country group to compute real values. The time and cost of export procedures show similar outcomes.
} 
evaluating port and transit as well as documentation and custom procedures and fees, they are largely independent of the size, the weight and the value of shipments. Thus lower fixed costs per shipment should be associated with less lumpy shipments. ${ }^{20}$

Table 2: Time and Cost of Import Procedures

\section{High-Income Countries}

Time to Import (days)

Cost to Import (constant USD)

Upper-Middle Income Countries

Time to Import (days)

Cost to Import (constant USD)

Lower-Middle Income Countries

Time to Import (days)

Cost to Import (constant USD)

Low Income Countries

Time to Import (days)

Cost to Import (constant USD)

\section{$20052013 \quad \%$ Change}

$13.9 \quad 11.5 \quad-17.3 \%$

$\$ 1,012 \quad \$ 980 \quad-3.2 \%$

$29.2 \quad 23 \quad-21.2 \%$

$\$ 1,362 \quad \$ 1,110 \quad-18.5 \%$

$37.5 \quad 27.6 \quad-26.4 \%$

$\$ 1,422 \quad \$ 1,090 \quad-23.3 \%$

$55.4 \quad 44.7 \quad-19.3 \%$

$\$ 2,292 \quad \$ 1,973 \quad-13.9 \%$

\section{Trade Volume and Welfare Effects of Interme- diation}

Intermediation in our model affects the trade volume and hence social welfare in the destination countries only because it involves a resource cost. In particular, the expected volume of shipments to a given country over two periods is $(A-c)$ without intermediation and simply $\left(A-c-c_{w}\right)$ with intermediation, independent of whether the intermediary is located in the exporting or the importing country or whether trade is lumpy or not. This is not a general result, of course, but one that is driven by our simplifying assumptions. These assumptions were useful, precisely because they allowed us to demonstrate why a supply chain may benefit by adding an intermediary to control inventory or allocate goods across markets, even if it reduces overall sales.

In this section we generalize the model to explore whether intermediation may have any effect on the expected volume of trade and social welfare beyond that stemming from the resource cost. For this purpose, we set $c_{w}=0$ and go back to the general setup of Section 3, where we do not distinguish between an export and an import intermediary. A reason to

\footnotetext{
${ }^{20}$ Documentation and custom procedures and fees are more independent of weight and value than port and transit procedures and fees. See Hornok and Koren (2014) for a discussion on this point and estimations with 2009 US and Spanish trade data showing that trade lumpiness is indeed lower for destinations with lower documentation and custom procedure and fees.
} 
suspect that intermediation has such effects is that intermediaries not only improve the allocation of goods across time and space, but they also allow the manufacturer to better exercise market power in the destination countries, and this may be detrimental to consumers. Specifically delegating pricing to an intermediary with better information about the realization of demand permits more exact pricing to extract surplus from consumers.

Consider the general demand function $p_{i t}=p_{i t}\left(s_{i t}\right)+\varepsilon_{i t}$, with $p_{i t}^{\prime}<0$ in country $i=\alpha, \beta$ at time $t=1,2$. Ignoring country and time subscripts, also assume:

$$
\begin{gathered}
p^{\prime \prime}(s) \geq 0 ; p^{\prime}(s)+s p^{\prime \prime}(s) \leq 0 ; p^{\prime \prime \prime}(s) \leq 0 ; 3 p^{\prime \prime}(s)+s p^{\prime \prime \prime}(s) \geq 0 ; \\
p^{\prime \prime}(s)+s p^{\prime \prime \prime}(s)-s\left(p^{\prime \prime}(s)\right)^{2} / p^{\prime}(s) \leq 0 .
\end{gathered}
$$

This assumption is satisfied for linear demand functions. Obviously, the linear demand case is a specific and extreme case of (A2) since it requires $p^{\prime \prime}=p^{\prime \prime \prime}=0 .{ }^{21}$

We prove the following result:

Proposition 6 Suppose that $c_{w}=0$ and the demand satisfies Assumption (A2). Then an intermediary reduces the expected volume of trade and expected social welfare in the destination country if trade is non-lumpy, and it increases the expected volume of trade and expected social welfare in the destination country if trade is lumpy.

Proof: see Appendix.

In the previous section, we established that an intermediary raises the profit of the supply chain more when trade is non-lumpy than when it is lumpy. Clearly, the intermediary's market power is better exercised in the presence of non-lumpy trade. Assumption (A2) establishes then that there are demand characteristics for which the intermediary's market power, through its ability to adjust wholesale prices, leads to lower overall expected sales and welfare as compared to a supply chain without intermediation. It is then not surprising that expected sales and welfare are higher with lumpy trade since the intermediary is unable to adjust its wholesale price in period 2. But the proposition goes further and establishes that expected sales and welfare are higher than without intermediation.

This result has interesting implications for trade, especially if we consider a world in which trade becomes less lumpy over time. Recall from the previous section that a reduction in lumpiness should lead to more intermediation. But with less lumpiness intermediaries may reduce social welfare. Hence trade liberalization in the form of less lumpy trade may have negative welfare consequences exactly when trade becomes intermediated.

\footnotetext{
${ }^{21}$ Assumption (A2) establishes, among other things, that $M R^{\prime}(s)=2 p^{\prime}(s)+s p^{\prime \prime}(s)<0$ and $M R^{\prime \prime}(s)=3 p^{\prime \prime}(s)+s p^{\prime \prime \prime}(s) \geq 0$.
} 


\section{Conclusions}

This paper shows that adding an intermediary to a supply chain is often an optimal strategy to follow for manufacturers in an environment where customers have to place orders before demand is known. This is the case even if adding an intermediary is costly and may even decrease the overall volume of sales and welfare. The benefit brought by an intermediary is shown to be especially important when demand volatility is high, as an intermediary is able to smooth shipments and to lower the need to maintain inventories within a supply chain with respect to one where such an intermediary is not present.

These are especially relevant results in an international trade context as lags between production and consumption, whether due to the nature of production, the location of that production, the transportation technology or border delays, make them far more prevalent than in a domestic market environment. It is then not surprising that export and import intermediaries continue to be important agents around the world. A corollary of our results is that during a dramatic shock such as the world financial crisis, the reduction in the volume of trade and the subsequent recovery can be expected to be softer within a supply chain involving intermediation than in one without it. This outcome has nothing to do with the ownership structure within the chain but everything to do with the incentives of different agents in the chain to maintain inventories.

But we go further by assigning distinct roles to import and export intermediaries. Import intermediaries are viewed as particularly useful whenever intertemporal arbitrage can be exploited, while export intermediaries are useful when international spatial arbitrage is likely to be present. An advantage of this approach is that it makes it possible to disentangle the relative role of an import and an export intermediary, something that has, to our knowledge, not been considered in the literature. The other advantage is its simplicity.

Showing that trade lumpiness affects the incentive to use intermediaries in general and the type of intermediary in particular allows us to claim that, insofar as trade nowadays is less lumpy than in the past, we should observe more intermediaries in international markets, not less, whether they are export or import intermediaries. But it is also true that, as international trade becomes less lumpy, we should observe a relatively higher proportion of export intermediaries. ${ }^{22}$ The argument that intermediaries are more useful than ever and this even if transport costs and trade barriers have come down is not entirely new. Belavina and Girotra (2012), for instance, argue that intermediaries help firms adapt to a volatile environment, even if they are

\footnotetext{
${ }^{22}$ See PRWeb (2006) for an example of a recent Chinese export intermediary (Chinavision Wholesale) for electronic products. The fact that this intermediary seems to accept any order, whatever its size, suggests non-lumpy trade.
} 
much larger than the intermediaries they typically use.

While testing directly some of our results is beyond the scope of this paper, it is interesting to note that our theoretical predictions are consistent with the empirical results about drop-shipping provided by Randall, Netessine and Rudi (2006). Drop-shipping is an arrangement whereby a retailer forwards buyers' orders to a wholesaler who then ships the product from its own inventory. This internet-based arrangement makes it possible for a retailer to avoid holding any inventory. The authors then compare this arrangement with one where the retailer is a traditional one that holds its own inventories. This is a similar structure to ours in so far as the dropshipping arrangement corresponds to the case where an intermediary takes over inventory control from downstream firms. The authors do find empirical evidence that traditional retailers who manage their own inventories face lower demand uncertainty than the retailers that rely on drop-shippers to control inventory. This is consistent with our result that using intermediaries to control inventories is optimal when there is high demand uncertainty. They also find that the greater the number of retailers, the greater the use of drop-shipping. Although our retailers are perfectly competitive and thus we have no particular result on that dimension, it is interesting to note that the fundamental reason why intermediaries might be needed is because retailers, as price takers, do not have the same incentives as a manufacturer or as an intermediary. In that sense this empirical finding is also consistent with our theoretical results. Finally, while most drop-shipping intermediaries supplying the US market are still located in the United States, improved logistics have led to the emergence of large drop-shipping intermediaries in China competing successfully in the US market. ${ }^{23}$ This is consistent with the notion that reduced lumpiness of international trade tends to give a larger role to export as opposed to import intermediaries.

We also note that vendor-managed inventory, an increasingly popular arrangement thanks to computer-based sales and inventory tracking technologies, is also very much consistent with the type of inventory control considered in this paper. With it, retailers delegate inventory control to manufacturers or wholesalers. There is often an international dimension to vendor-managed inventories. ${ }^{24}$

The final point is about the volume of trade and social welfare. While most of our results are derived in a simple environment that essentially keeps constant the volume of trade and social welfare regardless of the presence of intermediaries, we are still able to relax a few assumptions to show that the

\footnotetext{
${ }^{23}$ See PRWeb (2012) for the case of Ankara Wholesale, a firm based in China engaged in drop-shipping for electronic accessories.

${ }^{24}$ For instance Tibbett Logistics recently announced that it quadrupled the size of its automotive logisitcs operations in Romania in order to accommodate vendor-managed inventory operations for an undisclosed component manufacturer, including the inbound flow of components from Asian suppliers (Automotive Logistics, 2014).
} 
volume of trade and social welfare can either go up or down depending on the demand characteristics. In particular we show that there is a fundamental trade-off between an efficient intertemporal allocation of products and the exploitation of market power associated with intermediaries and that this trade-off is influenced by product characteristics (reflected by the shape of the demand) and the degree of international trade lumpiness. Lumpiness, in particular, tends to limit the ability to exploit market power, simply because an intermediary is forced to deal with an uncertain intertemporal allocation of products out of a single shipment. Using an intermediary in that case may be enough to bring about a higher trade volume and welfare.

There is clearly more to do both at the theoretical and at the empirical level as intermediation, especially in international markets, is here to stay. One message coming from this paper is the result that trade flows, trade volatility and inventory size depend on who engages in trade and who carries inventories. In other words, the micro-structure matters for international trade dynamics. To our knowledge, this point has not been made in the literature.

\section{Appendix}

\subsection{Proof of Proposition 3}

The intermediary earns a total revenue in the two countries of

$$
\left(A-s_{\alpha}+\varepsilon_{\alpha}\right) s_{\alpha}+\left(A-s_{\beta}+\varepsilon_{\beta}\right) s_{\beta},
$$

where $s_{\alpha}=\frac{2 q+\left(\varepsilon_{\alpha}-\varepsilon_{\beta}\right)}{4}$ and $s_{\beta}=\frac{2 q-\left(\varepsilon_{\alpha}-\varepsilon_{\beta}\right)}{4}$. Hence the expected revenue of the intermediary is

$$
E(R)=\int_{-d}^{d} \int_{-d}^{d} \frac{8 A q+4 q\left(\varepsilon_{\alpha}+\varepsilon_{\beta}\right)-4 q^{2}+\left(\varepsilon_{\alpha}-\varepsilon_{\beta}\right)^{2}}{8} f\left(\varepsilon_{\alpha}, \varepsilon_{\beta}\right) d \varepsilon_{\alpha} d \varepsilon_{\beta}
$$

Given a producer price $P$ and transfer $T$, the export intermediary's problem can be written as

$$
\max _{q} E(R)-q\left(P+c_{w}\right)-T
$$

The first-order condition for this problem yields $q=A-\left(P+c_{w}\right)$, and the expected profit of the export intermediary thus is

$$
\begin{aligned}
& \frac{\left[A-\left(P+c_{w}\right)\right]^{2}}{2}+\int_{-d}^{d} \int_{-d}^{d} \frac{\left(\varepsilon_{\alpha}-\varepsilon_{\beta}\right)^{2}}{8} f\left(\varepsilon_{\alpha}, \varepsilon_{\beta}\right) d \varepsilon_{\alpha} d \varepsilon_{\beta}-T \\
= & \frac{\left[A-\left(P+c_{w}\right)\right]^{2}}{2}+\frac{d^{2}}{12}(1-\rho)-T
\end{aligned}
$$


where we used the facts that

$$
\begin{aligned}
& \int_{-d}^{d} \int_{-d}^{d}\left(\varepsilon_{\alpha}+\varepsilon_{\beta}\right) f\left(\varepsilon_{\alpha}, \varepsilon_{\beta}\right) d \varepsilon_{\alpha} d \varepsilon_{\beta} \\
= & \int_{-d}^{d} \int_{-d}^{d} \varepsilon_{\alpha} f\left(\varepsilon_{\alpha}, \varepsilon_{\beta}\right) d \varepsilon_{\alpha} d \varepsilon_{\beta}+\int_{-d}^{d} \int_{-d}^{d} \varepsilon_{\beta} f\left(\varepsilon_{\alpha}, \varepsilon_{\beta}\right) d \varepsilon_{\alpha} d \varepsilon_{\beta} \\
= & \int_{-d}^{d} \varepsilon_{\alpha} f_{\alpha}\left(\varepsilon_{\alpha}\right) d \varepsilon_{\alpha}+\int_{-d}^{d} \varepsilon_{\beta} f_{\beta}\left(\varepsilon_{\beta}\right) d \varepsilon_{\beta} \\
= & \int_{-d}^{d} \varepsilon_{\alpha} \frac{1}{2 d} d \varepsilon_{\alpha}+\int_{-d}^{d} \varepsilon_{\beta} \frac{1}{2 d} d \varepsilon_{\beta}=0,
\end{aligned}
$$

and

$$
\begin{aligned}
& \int_{-d}^{d} \int_{-d}^{d}\left(\varepsilon_{\alpha}-\varepsilon_{\beta}\right)^{2} f\left(\varepsilon_{\alpha}, \varepsilon_{\beta}\right) d \varepsilon_{\alpha} d \varepsilon_{\beta} \\
= & \int_{-d}^{d} \int_{-d}^{d}\left(\varepsilon_{\alpha}^{2}+\varepsilon_{\beta}^{2}-2 \varepsilon_{\alpha} \varepsilon_{\beta}\right) f\left(\varepsilon_{\alpha}, \varepsilon_{\beta}\right) d \varepsilon_{\alpha} d \varepsilon_{\beta} \\
= & \int_{-d}^{d} \varepsilon_{\alpha}^{2} \frac{1}{2 d} d \varepsilon_{\alpha}+\int_{-d}^{d} \varepsilon_{\beta}^{2} \frac{1}{2 d} d \varepsilon_{\beta}-2 E\left(\varepsilon_{\alpha} \varepsilon_{\beta}\right) \\
= & \frac{2 d^{2}}{3}-2\left[\operatorname{cov}\left(\varepsilon_{\alpha}, \varepsilon_{\beta}\right)+E\left(\varepsilon_{\alpha}\right) E\left(\varepsilon_{\beta}\right)\right] \\
= & \frac{2 d^{2}}{3}-2 \rho \sigma_{\alpha} \sigma_{\beta} \\
= & \frac{2 d^{2}}{3}(1-\rho) .
\end{aligned}
$$

Finally the manufacturer has to set $P$ and $T$, and it is optimal for him to set $P=c$ and to demand a transfer that extracts the intermediary's entire profit. Summing across both periods, the total expected manufacturer profit per destination market when exporting through an export intermediary is therefore given by (5). The proof is completed by comparing this profit with (4).

\subsection{Equilibrium With Lumpy Trade}

\subsubsection{No Intermediation}

When demand shock $\varepsilon_{1}$ becomes resolved in period 1, downstream firms sell in period 1 as long as the first period price $p_{1}$ exceeds the expected second-period price $E\left(p_{2}\right)$; otherwise, they will hold goods inventory for sale in period 2. Hence in an equilibrium $p_{1}=E\left(p_{2}\right)$, or $A-s_{1}+\varepsilon_{1}=$ $E\left(A-s_{2}+\varepsilon_{2}\right)=A-s_{2}$. Assuming that downstream firms have ordered 
quantity $Q$ so that $s_{1}+s_{2}=Q$, we have $s_{1}=\left(Q+\varepsilon_{1}\right) / 2$ and $s_{2}=$ $\left(Q-\varepsilon_{1}\right) / 2$. The first-period price (and expected second-period price) is hence

$$
\bar{p}=A-s_{1}+\varepsilon_{1}=\frac{2 A-Q+\varepsilon_{1}}{2},
$$

so that the total revenue after observing demand in period 1 is

$$
R=r_{1}+E_{1}\left(r_{2}\right)=\bar{p} Q=\frac{\left(2 A-Q+\varepsilon_{1}\right) Q}{2} .
$$

Given consumer price $\bar{p}$ and producer price $P$, downstream firms will order goods until their expected profit is zero:

$$
\int_{-d}^{d} \frac{\left(2 A-Q+\varepsilon_{1}\right) Q}{2} \frac{1}{2 d} d \varepsilon_{1}-P Q=0 .
$$

The manufacturer maximizes expected profit $P Q-c Q$. Solving the corresponding first-order condition,

$$
\frac{1}{2 d} \int_{-d}^{d} \frac{2 A-2 Q+\varepsilon_{1}}{2} d \varepsilon_{1}-c=0,
$$

yields as optimal total output $Q=A-c$. So for the manufacturer the expected profit from exporting directly to one of the countries is given by $(3)$.

\subsubsection{Import Intermediary}

As we know from the case of non-lumpy trade, the intermediary will earn an expected revenue in period 2 given by $\left(A-s_{2}\right) s_{2}$, and revenue $\left(A-s_{1}+\varepsilon_{1}\right) s_{1}$ in period 1 . Hence the total expected revenue of the intermediary after observing $\varepsilon_{1}$ is:

$$
E(R)=\left(A-s_{1}+\varepsilon_{1}\right) s_{1}+\left(A-s_{2}\right) s_{2},
$$

where $s_{1}+s_{2}=Q$ and $Q$ is the initial quantity ordered by the intermediary.

In period 1 , the cost of ordering quantity $Q$ is sunk and, given the revealed demand shock $\varepsilon_{1}$, the import intermediary allocates output across periods until the marginal revenue in period 1 is equal to expected marginal revenue in period 2. This means $A-2 s_{1}+\varepsilon_{1}=A-2 s_{2}$, and since $s_{1}+s_{2}=Q$, then $s_{1}=\left(2 Q+\varepsilon_{1}\right) / 4$ and $s_{2}=\left(2 Q-\varepsilon_{1}\right) / 4$. Using these values in (15), we obtain as total expected revenue of the import intermediary after observing $\varepsilon_{1}$ :

$$
\begin{aligned}
E(R) & =\frac{\left(4 A-2 Q+3 \varepsilon_{1}\right)}{4} \frac{\left(2 Q+\varepsilon_{1}\right)}{4}+\frac{\left(4 A-2 Q+\varepsilon_{1}\right)}{4} \frac{\left(2 Q-\varepsilon_{1}\right)}{4}(16) \\
& =\frac{4 Q\left(2 A+\varepsilon_{1}\right)+\varepsilon_{1}^{2}-4 Q^{2}}{8}
\end{aligned}
$$


Before observing $\varepsilon_{1}$, the import intermediary chooses $Q$ to maximize

$$
\int_{-d}^{d} \frac{4 Q\left(2 A+\varepsilon_{1}\right)+\varepsilon_{1}^{2}-4 Q^{2}}{8} \frac{1}{2 d} d \varepsilon_{1}-\left(P+c_{w}\right) Q-T .
$$

From the first-order condition

$$
\int_{-d}^{d} \frac{4\left(2 A+\varepsilon_{1}\right)-8 Q}{8} \frac{1}{2 d} d \varepsilon_{1}-\left(P+c_{w}\right)=0,
$$

we obtain the optimal order quantity $Q=A-\left(P+c_{w}\right)$ and a total expected profit of the import intermediary of

$$
\frac{\left[A-\left(P+c_{w}\right)\right]^{2}}{2}+\frac{d^{2}}{24}-T .
$$

As in the case of non-lumpy trade the manufacturer sets $P=c$, and extracts the intermediary's profit through the transfer $T$. The total expected manufacturer profit from exporting to one of the countries via an import intermediary is given by (6).

\subsubsection{Export Intermediary}

When facing wholesale price $w_{i}$, downstream firms in country $i=\alpha, \beta$ will order goods until their expected profit is zero and thus

$$
\frac{\left(2 A-Q_{i}+\varepsilon_{i 1}\right)}{2} Q_{i}-w_{i} Q_{i}=0
$$

where $\frac{\left(2 A-Q_{i}+\varepsilon_{i 1}\right)}{2} Q_{i}$ is the revenue for downstream firms from equation (12). The total revenue that the export intermediary can generate by selling to the downstream firms in the two countries then is

$$
R=\frac{\left(2 A-Q_{\alpha}+\varepsilon_{\alpha 1}\right)}{2} Q_{\alpha}+\frac{\left(2 A-Q_{\beta}+\varepsilon_{\beta 1}\right)}{2} Q_{\beta},
$$

where $Q_{\alpha}$ and $Q_{\beta}$ are the quantities of products allocated to countries $\alpha$ and $\beta$, respectively, and $Q_{\alpha}+Q_{\beta}=Q$. After $Q$ has been allocated across the two countries, the downstream firms in country $i$ divide quantity $Q_{i}$ across periods so as to equalize the first period price and the expected secondperiod price as has been discussed above.

Consider the optimal strategy of the export intermediary after observing the first-period demand shocks $\varepsilon_{\alpha 1}$ and $\varepsilon_{\beta 1}$. The export intermediary sets wholesale prices so that the downstream firms order the quantities $Q_{\alpha}$ and $Q_{\beta}$ that equalize marginal revenues in the two countries is $2 A-2 Q_{\alpha}+\varepsilon_{\alpha 1}=$ $2 A-2 Q_{\beta}+\varepsilon_{\beta 1}$. Using $Q_{\alpha}+Q_{\beta}=Q$, we obtain $Q_{\alpha}=\left(2 Q+\left(\varepsilon_{\alpha 1}-\varepsilon_{\beta 1}\right)\right) / 4$ and $Q_{b}=\left(2 Q-\left(\varepsilon_{\alpha 1}-\varepsilon_{\beta 1}\right)\right) / 4$. Using these values in (21) and taking expectations, the total expected revenue of the export intermediary is 


$$
\int_{-d}^{d} \int_{-d}^{d} \frac{16 A Q+4 Q\left(\varepsilon_{\alpha 1}+\varepsilon_{\beta 1}\right)-4 Q^{2}+\left(\varepsilon_{\alpha 1}-\varepsilon_{\beta 1}\right)^{2}}{16} f\left(\varepsilon_{\alpha t}, \varepsilon_{\beta t}\right) d \varepsilon_{\alpha 1} d \varepsilon_{\beta 1} .
$$

As what we have calculated in (8),

$$
\int_{-d}^{d} \int_{-d}^{d}\left(\varepsilon_{\alpha 1}+\varepsilon_{\beta 1}\right) f\left(\varepsilon_{\alpha t}, \varepsilon_{\beta t}\right) d \varepsilon_{\alpha 1} d \varepsilon_{\beta 1}=0
$$

and

$$
\int_{-d}^{d} \int_{-d}^{d}\left(\varepsilon_{\alpha 1}-\varepsilon_{\beta 1}\right)^{2} f\left(\varepsilon_{\alpha t}, \varepsilon_{\beta t}\right) d \varepsilon_{\alpha 1} d \varepsilon_{\beta 1}=\frac{2 d^{2}}{3}(1-\rho)
$$

Thus (22) reduces to

$$
\frac{4 A Q-Q^{2}}{4}+\frac{d^{2}}{24}(1-\rho) .
$$

Setting marginal revenue equal to marginal cost $\left(P+c_{w}\right)$ yields the intermediary's optimal order $Q=2\left(A-\left(P+c_{w}\right)\right)$. We can then compute the intermediary's expected profit, which is

$$
\left[A-\left(P+c_{w}\right)\right]^{2}+\frac{d^{2}}{24}(1-\rho)-T .
$$

Since the manufacturer will optimally choose $P=c$ and extract the wholesaler's profit through the transfer $T$, the expected profit of the manufacturer from exporting to one of the countries is equal to (7).

\subsection{Proof of Proposition 6}

\subsubsection{Non-lumpy Trade}

At the beginning of period 2, denote the optimal inventory level as $I_{2}^{o}$. From the analysis above, we know that this optimal inventory level should be the same with direct exports and trade through an import intermediary. $I_{2}^{o}$ is determined by the condition $p\left(I_{2}^{o}\right)+I_{2}^{o} p^{\prime}\left(I_{2}^{o}\right)=c$. In period 1 after demand has been revealed, "price equalization" across periods by downstream firms in the case of direct exports implies sales in period $1, s_{1}^{\text {direct }}\left(\varepsilon_{1}\right)$, such that:

$$
p\left(s_{1}^{\text {direct }}\right)+\varepsilon_{1}=p\left(I_{2}^{o}\right) .
$$

"Marginal revenue equalization" across periods by an import intermediary implies first-period sales of $s_{1}^{i m}\left(\varepsilon_{1}\right)$, such that

$$
p\left(s_{1}^{i m}\right)+s_{1}^{i m} p^{\prime}\left(s_{1}^{i m}\right)+\varepsilon_{1}=p\left(I_{2}^{o}\right)+I_{2}^{o} p^{\prime}\left(I_{2}^{o}\right) .
$$


Notice that applying the implicit function theorem to (26) we obtain:

$$
\frac{\partial s_{1}^{i m}\left(\varepsilon_{1}\right)}{\partial \varepsilon_{1}}=-\frac{1}{2 p^{\prime}\left(s_{1}^{i m}\right)+s_{1}^{i m} p^{\prime \prime}\left(s_{1}^{i m}\right)}>0,
$$

and

$$
\begin{aligned}
\frac{\partial^{2} s_{1}^{i m}\left(\varepsilon_{1}\right)}{\partial \varepsilon_{1}^{2}} & =-\frac{-\left[3 p^{\prime \prime}\left(s_{1}^{i m}\right)+s_{1}^{i m} p^{\prime \prime \prime}\left(s_{1}^{i m}\right)\right] \frac{\partial s_{1}^{i m}\left(\varepsilon_{1}\right)}{\partial \varepsilon_{1}}}{\left[2 p^{\prime}\left(s_{1}^{i m}\right)+s_{1}^{i m} p^{\prime \prime}\left(s_{1}^{i m}\right)\right]^{2}} \\
& =-\frac{3 p^{\prime \prime}\left(s_{1}^{i m}\right)+s_{1}^{i m} p^{\prime \prime \prime}\left(s_{1}^{i m}\right)}{\left[2 p^{\prime}\left(s_{1}^{i m}\right)+s_{1}^{i m} p^{\prime \prime}\left(s_{1}^{i m}\right)\right]^{3}}>0 .
\end{aligned}
$$

The proof now proceeds by proving several lemmas. The first two lemmas establish the result that the expected first-period price is greater in the case of an import intermediary than in the case of direct exports.

Lemma $1 s_{1}^{i m} p^{\prime}\left(s_{1}^{i m}\right)$ is concave in $\varepsilon_{1}$; or equivalently, $-s_{1}^{i m} p^{\prime}\left(s_{1}^{i m}\right)$ is convex in $\varepsilon_{1}$.

\section{Proof:}

$$
\begin{aligned}
\frac{\partial}{\partial \varepsilon_{1}}\left[s_{1}^{i m} p^{\prime}\left(s_{1}^{i m}\right)\right]= & {\left[p^{\prime}\left(s_{1}^{i m}\right)+s_{1}^{i m} p^{\prime \prime}\left(s_{1}^{i m}\right)\right] \frac{\partial s_{1}^{i m}\left(\varepsilon_{1}\right)}{\partial \varepsilon_{1}} } \\
\frac{\partial^{2}}{\partial \varepsilon_{1}^{2}}\left[s_{1}^{i m} p^{\prime}\left(s_{1}^{i m}\right)\right]= & {\left[2 p^{\prime \prime}\left(s_{1}^{i m}\right)+s_{1}^{i m} p^{\prime \prime \prime}\left(s_{1}^{i m}\right)\right]\left(\frac{\partial s_{1}^{i m}}{\partial \varepsilon_{1}}\right)^{2} } \\
& +\left[p^{\prime}\left(s_{1}^{i m}\right)+s_{1}^{i m} p^{\prime \prime}\left(s_{1}^{i m}\right)\right] \frac{\partial^{2} s_{1}^{i m}}{\partial \varepsilon_{1}^{2}} \\
= & \frac{2 p^{\prime \prime}\left(s_{1}^{i m}\right)+s_{1}^{i m} p^{\prime \prime \prime}\left(s_{1}^{i m}\right)}{\left[2 p^{\prime}\left(s_{1}^{i m}\right)+s_{1}^{i m} p^{\prime \prime}\left(s_{1}^{i m}\right)\right]^{2}} \\
& -\frac{\left[3 p^{\prime \prime}\left(s_{1}^{i m}\right)+s_{1}^{i m} p^{\prime \prime \prime}\left(s_{1}^{i m}\right)\right]\left[p^{\prime}\left(s_{1}^{i m}\right)+s_{1}^{i m} p^{\prime \prime}\left(s_{1}^{i m}\right)\right]}{\left[2 p^{\prime}\left(s_{1}^{i m}\right)+s_{1}^{i m} p^{\prime \prime}\left(s_{1}^{i m}\right)\right]^{3}} \\
& \left\{\frac{\left[2 p^{\prime \prime}\left(s_{1}^{i m}\right)+s_{1}^{i m} p^{\prime \prime \prime}\left(s_{1}^{i m}\right)\right]\left[2 p^{\prime}\left(s_{1}^{i m}\right)+s_{1}^{i m} p^{\prime \prime}\left(s_{1}^{i m}\right)\right]}{\left[3 p^{\prime \prime}\left(s_{1}^{i m}\right)+s_{1}^{i m} p^{\prime \prime \prime}\left(s_{1}^{i m}\right)\right]\left[p^{\prime}\left(s_{1}^{i m}\right)+s_{1}^{i m} p^{\prime \prime}\left(s_{1}^{i m}\right)\right]}\right\} \\
= & \frac{K\left(s_{1}^{i m} p^{\prime \prime}\left(s_{1}^{i m}\right)\right]^{3}}{\left[2 p^{\prime}\left(s_{1}^{i m}\right)+s_{1}^{i m} p^{\prime \prime}\left(s_{1}^{i m}\right)\right]^{3}}
\end{aligned}
$$

where

$$
\begin{aligned}
K(s)= & {\left[4 p^{\prime} p^{\prime \prime}+2 s\left(p^{\prime \prime}\right)^{2}+2 s p^{\prime} p^{\prime \prime \prime}+s^{2} p^{\prime \prime} p^{\prime \prime \prime}\right] } \\
& -\left[3 p^{\prime} p^{\prime \prime}+3 s\left(p^{\prime \prime}\right)^{2}+s p^{\prime} p^{\prime \prime \prime}+s^{2} p^{\prime \prime} p^{\prime \prime \prime}\right] \\
= & p^{\prime} p^{\prime \prime}-s\left(p^{\prime \prime}\right)^{2}+s p^{\prime} p^{\prime \prime \prime} .
\end{aligned}
$$


By $(\mathrm{A} 2) 0 \leq 3 p^{\prime \prime}(s)+s p^{\prime \prime \prime}(s) \leq \frac{s\left[p^{\prime \prime}(s)\right]^{2}}{p^{\prime}(s)}+2 p^{\prime \prime}(s)$,

$$
\begin{aligned}
& \Rightarrow p^{\prime \prime}+s p^{\prime \prime \prime} \leq \frac{s\left(p^{\prime \prime}\right)^{2}}{p^{\prime}} \\
& \Leftrightarrow p^{\prime} p^{\prime \prime}-s\left(p^{\prime \prime}\right)^{2}+s p^{\prime} p^{\prime \prime \prime} \geq 0 .
\end{aligned}
$$

Therefore $\frac{\partial^{2}}{\partial \varepsilon_{1}^{2}}\left[s_{1}^{i m} p^{\prime}\left(s_{1}^{i m}\right)\right]=\frac{1}{\left[2 p^{\prime}\left(s_{1}^{i m}\right)+s_{1}^{i m} p^{\prime \prime}\left(s_{1}^{i m}\right)\right]^{3}} K\left(s_{1}^{i m}\right) \leq 0$.

Lemma $2 E\left[p\left(s_{1}^{i m}\right)\right] \geq E\left[p\left(s_{1}^{\text {direct }}\right)\right]$

\section{Proof:}

$$
\begin{aligned}
& E\left[p\left(s_{1}^{i m}\right)\right]-E\left[p\left(s_{1}^{\text {direct }}\right)\right] \\
= & E\left[I_{2}^{o} p^{\prime}\left(I_{2}^{o}\right)-s_{1}^{i m} p^{\prime}\left(s_{1}^{i m}\right)\right] \\
= & I_{2}^{o} p^{\prime}\left(I_{2}^{o}\right)-E\left[s_{1}^{i m} p^{\prime}\left(s_{1}^{i m}\right)\right]
\end{aligned}
$$

Notice that $E\left(\varepsilon_{1}\right)=\bar{\varepsilon}=0$, and $s_{1}^{i m}(\bar{\varepsilon})=I_{2}^{o}$. Using Lemma 1 and Jensen's inequality, ${ }^{25}$ we have $E\left[-s_{1}^{i m} p^{\prime}\left(s_{1}^{i m}\right)\right] \geq-s_{1}^{i m}(\bar{\varepsilon}) p^{\prime}\left[s_{1}^{i m}(\bar{\varepsilon})\right]=-I_{2}^{o} p^{\prime}\left(I_{2}^{o}\right)$. This proves that $E\left[p\left(s_{1}^{\text {im }}\right)\right]-E\left[p\left(s_{1}^{\text {direct }}\right)\right] \geq 0$.

The next two lemmas establish that expected first-period sales are lower with an import intermediary than with direct exports.

Lemma 3 If $\varepsilon_{1}<0$, then $s_{1}^{\text {direct }}<s_{1}^{\text {im }}<I_{2}^{o}$; if $\varepsilon_{1}>0$, then $s_{1}^{\text {direct }}>s_{1}^{\text {im }}>$ $I_{2}^{o}$.

\section{Proof:}

$$
\begin{aligned}
p\left(s_{1}^{i m}\right)-p\left(s_{1}^{\text {direct }}\right) & =p\left(I_{2}^{o}\right)+I_{2}^{o} p^{\prime}\left(I_{2}^{o}\right)-s_{1}^{i m} p^{\prime}\left(s_{1}^{i m}\right)-p\left(I_{2}^{o}\right) \\
& =I_{2}^{o} p^{\prime}\left(I_{2}^{o}\right)-s_{1}^{i m} p^{\prime}\left(s_{1}^{i m}\right) .
\end{aligned}
$$

In the case of $\varepsilon_{1}<0$ : from (26) we know $s_{1}^{i m}<I_{2}^{o}$. Since by (A2) $p^{\prime}(s)+$ $s p^{\prime \prime}(s)<0$, we have $I_{2}^{o} p^{\prime}\left(I_{2}^{o}\right)-s_{1}^{i m} p^{\prime}\left(s_{1}^{i m}\right)<0$, and thus $s_{1}^{\text {im }}>s_{1}^{\text {direct }}$. Similarly for $\varepsilon_{1}>0$ we can prove $I_{2}^{o}<s_{1}^{\text {im }}<s_{1}^{\text {direct }}$.

Lemma $4 E\left[s_{1}^{\text {im }}\right] \leq E\left[s_{1}^{\text {direct }}\right]$

Proof: The mean value theorem tells us that for any $\varepsilon_{1}$, there is a $\zeta\left(\varepsilon_{1}\right) \in$ $\left[\min \left(s_{1}^{\text {direct }}, s_{1}^{\text {im }}\right), \max \left(s_{1}^{\text {direct }}, s_{1}^{\text {im }}\right)\right]$, such that $p^{\prime}(\zeta)=\frac{p\left(s_{1}^{\text {im }}\right)-p\left(s_{1}^{\text {direct }}\right)}{s_{1}^{\text {im }}-s_{1}^{\text {direct }}}$. This implies

$$
\begin{aligned}
s_{1}^{\text {im }}-s_{1}^{\text {direct }} & =\frac{p\left(s_{1}^{\text {im }}\right)-p\left(s_{1}^{\text {direct }}\right)}{p^{\prime}(\zeta)} \\
& =\frac{I_{2}^{o} p^{\prime}\left(I_{2}^{o}\right)-s_{1}^{i m} p^{\prime}\left(s_{1}^{i m}\right)}{p^{\prime}(\zeta)} .
\end{aligned}
$$

\footnotetext{
${ }^{25}$ If $X$ is a random variable and $\varphi$ is a convex function, then $\varphi[E(X)] \leq E[\varphi(X)]$.
} 
Notice that

$$
\frac{d}{d s}\left[\frac{1}{p^{\prime}(s)}\right]=-\frac{p^{\prime \prime}(s)}{\left[p^{\prime}(s)\right]^{2}}<0
$$

and consider two cases: If $\varepsilon_{1}<0$, then from Lemma 3 we have $s_{1}^{\text {direct }}<\zeta<$ $s_{1}^{i m}<I_{2}^{o}$ and $I_{2}^{o} p^{\prime}\left(I_{2}^{o}\right)-s_{1}^{i m} p^{\prime}\left(s_{1}^{i m}\right)<0$. If $\varepsilon_{1}>0$, then Lemma 3 implies $I_{2}^{o}<s_{1}^{i m}<\zeta<s_{1}^{\text {direct }}$ and $I_{2}^{o} p^{\prime}\left(I_{2}^{o}\right)-s_{1}^{i m} p^{\prime}\left(s_{1}^{i m}\right)>0$. Hence in both cases, we have

$$
\begin{aligned}
s_{1}^{i m}-s_{1}^{\text {direct }} & =\frac{I_{2}^{o} p^{\prime}\left(I_{2}^{o}\right)-s_{1}^{i m} p^{\prime}\left(s_{1}^{i m}\right)}{p^{\prime}(\zeta)} \\
& \leq \frac{I_{2}^{o} p^{\prime}\left(I_{2}^{o}\right)-s_{1}^{i m} p^{\prime}\left(s_{1}^{i m}\right)}{p^{\prime}\left(I_{2}^{o}\right)} \\
& =I_{2}^{o}-\frac{s_{1}^{i m} p^{\prime}\left(s_{1}^{i m}\right)}{p^{\prime}\left(I_{2}^{o}\right)} .
\end{aligned}
$$

Taking expectations yields

$$
\begin{aligned}
E\left[s_{1}^{i m}-s_{1}^{\text {direct }}\right] & \leq E\left[I_{2}^{o}-\frac{s_{1}^{i m} p^{\prime}\left(s_{1}^{i m}\right)}{p^{\prime}\left(I_{2}^{o}\right)}\right] \\
& =I_{2}^{o}-\frac{1}{p^{\prime}\left(I_{2}^{o}\right)} E\left[s_{1}^{i m} p^{\prime}\left(s_{1}^{i m}\right)\right] .
\end{aligned}
$$

Since we know from the proof of Lemma 2 that $E\left[s_{1}^{i m} p^{\prime}\left(s_{1}^{i m}\right)\right] \leq I_{2}^{o} p^{\prime}\left(I_{2}^{o}\right)$, we can state

$$
\begin{aligned}
E\left[s_{1}^{i m}-s_{1}^{\text {direct }}\right] & \leq I_{2}^{o}-\frac{1}{p^{\prime}\left(I_{2}^{o}\right)} I_{2}^{o} p^{\prime}\left(I_{2}^{o}\right) \\
& =0 .
\end{aligned}
$$

Finally notice that in our two-period model, $s_{2}^{i m}=s_{2}^{\text {direct }}$ and $p\left(s_{2}^{i m}\right)=$ $p\left(s_{2}^{\text {direct }}\right)$. Hence Lemmas 2 and 4 imply directly that an import intermediary reduces the expected volume of trade and consumer surplus relative to direct exports if trade is non-lumpy. Since the expected profits of the import intermediary and downstream customers are zero, social welfare in the destination countries decreases when inventory is controlled by an import intermediary.

\subsubsection{Lumpy Trade}

Suppose that quantity $Q$ has been delivered to downstream firms or an import intermediary, respectively. In period 1 after demand has been revealed, "price equalization" across periods by downstream firms in the case of direct exports implies sales in period $1, s_{1}^{\text {direct }}\left(\varepsilon_{1}\right)$, such that:

$$
p\left(s_{1}^{\text {direct }}\right)+\varepsilon_{1}=p\left(Q-s_{1}^{\text {direct }}\right),
$$


where

$$
\begin{aligned}
\frac{\partial s_{1}^{\text {direct }}}{\partial Q} & =\frac{p^{\prime}\left(Q-s_{1}^{\text {direct }}\right)}{p^{\prime}\left(s_{1}^{\text {direct }}\right)+p^{\prime}\left(Q-s_{1}^{\text {direct }}\right)} \\
& =\frac{1}{\frac{p^{\prime}\left(s_{1}^{\text {direct }}\right)}{p^{\prime}\left(Q-s_{1}^{\text {direct }}\right)}+1}=\frac{1}{\frac{p^{\prime}\left(s_{1}^{\text {direct }}\right)}{p^{\prime}\left(s_{2}^{\text {direct }}\right)}+1} .
\end{aligned}
$$

"Marginal revenue equalization" across periods by an import intermediary implies first-period sales of $s_{1}^{i m}\left(\varepsilon_{1}\right)$, such that

$$
p\left(s_{1}^{i m}\right)+s_{1}^{i m} p^{\prime}\left(s_{1}^{i m}\right)+\varepsilon_{1}=p\left(Q-s_{1}^{i m}\right)+\left(Q-s_{1}^{i m}\right) p^{\prime}\left(Q-s_{1}^{i m}\right),
$$

where

$$
\begin{aligned}
\frac{\partial s_{1}^{i m}}{\partial Q} & =\frac{2 p^{\prime}\left(Q-s_{1}^{i m}\right)+\left(Q-s_{1}^{i m}\right) p^{\prime \prime}\left(Q-s_{1}^{i m}\right)}{2 p^{\prime}\left(s_{1}^{i m}\right)+s_{1}^{i m} p^{\prime \prime}\left(s_{1}^{i m}\right)+2 p^{\prime}\left(Q-s_{1}^{i m}\right)+\left(Q-s_{1}^{i m}\right) p^{\prime \prime}\left(Q-s_{1}^{i m}\right)} \\
& =\frac{1}{\frac{2 p^{\prime}\left(s_{1}^{i m}\right)+s_{1}^{i m} p^{\prime \prime}\left(s_{1}^{i m}\right)}{2 p^{\prime}\left(Q-s_{1}^{i m}\right)+\left(Q-s_{1}^{i m}\right) p^{\prime \prime}\left(Q-s_{1}^{i m}\right)}+1}=\frac{1}{\frac{M R^{\prime}\left(s_{1}^{i m}\right)}{M R^{\prime}\left(s_{2}^{i m}\right)}+1} .
\end{aligned}
$$

In order to compare the expected volume of trade in the case of direct exports with that in the case of an import intermediary, we need to know the sum of marginal revenues in periods 1 and 2 for a given inventory level $Q$. Since marginal costs are the same in both cases, the case with the higher expected total marginal revenue yields the larger trade volume in equilibrium.

Using (28), the sum of marginal revenues in the case of an import intermediary is

$$
\begin{aligned}
& \sum M R^{i m}=\frac{\partial}{\partial Q}\left[p\left(s_{1}^{i m}\right) s_{1}^{i m}+\varepsilon_{1} s_{1}^{i m}+\left(Q-s_{1}^{i m}\right) p\left(Q-s_{1}^{i m}\right)\right] \\
& =\left[\begin{array}{c}
p\left(s_{1}^{i m}\right)+s_{1}^{i m} p^{\prime}\left(s_{1}^{i m}\right)+\varepsilon_{1}-p\left(Q-s_{1}^{i m}\right) \\
-\left(Q-s_{1}^{i m}\right) p^{\prime}\left(Q-s_{1}^{i m}\right)
\end{array}\right] \frac{\partial s_{1}^{i m}}{\partial Q} \\
& +p\left(Q-s_{1}^{i m}\right)+\left(Q-s_{1}^{i m}\right) p^{\prime}\left(Q-s_{1}^{i m}\right) \\
& =\left[p\left(s_{1}^{i m}\right)+s_{1}^{i m} p^{\prime}\left(s_{1}^{i m}\right)+\varepsilon_{1}\right] \frac{\partial s_{1}^{i m}}{\partial Q} \\
& +\left[p\left(Q-s_{1}^{i m}\right)+\left(Q-s_{1}^{i m}\right) p^{\prime}\left(Q-s_{1}^{i m}\right)\right]\left(1-\frac{\partial s_{1}^{i m}}{\partial Q}\right) \\
& =\left[M R\left(s_{1}^{i m}\right)+\varepsilon_{1}\right] \frac{\partial s_{1}^{i m}}{\partial Q}+M R\left(s_{2}^{i m}\right)\left(1-\frac{\partial s_{1}^{i m}}{\partial Q}\right) \text {. }
\end{aligned}
$$


From (27) the sum of marginal revenues in the case of direct exports is

$$
\begin{aligned}
\sum M R^{\text {direct }}= & {\left[p\left(s_{1}^{\text {direct }}\right)+s_{1}^{\text {direct }} p^{\prime}\left(s_{1}^{\text {direct }}\right)+\varepsilon_{1}\right] \frac{\partial s_{1}^{\text {direct }}}{\partial Q} } \\
& +\left[p\left(Q-s_{1}^{\text {direct }}\right)+\left(Q-s_{1}^{\text {direct }}\right) p^{\prime}\left(Q-s_{1}^{\text {direct }}\right)\right] \\
& \times\left(1-\frac{\partial s_{1}^{\text {direct }}}{\partial Q}\right) \\
= & {\left[M R\left(s_{1}^{\text {direct }}\right)+\varepsilon_{1}\right] \frac{\partial s_{1}^{\text {direct }}}{\partial Q}+M R\left(s_{2}^{\text {direct }}\right) } \\
& \times\left(1-\frac{\partial s_{1}^{\text {direct }}}{\partial Q}\right) .
\end{aligned}
$$

We can thus write the difference of the sums of marginal revenues as

$$
\begin{aligned}
\Delta= & \sum M R^{\text {direct }}-\sum M R^{\text {im }} \\
= & M R\left(s_{1}^{\text {direct }}\right) \frac{\partial s_{1}^{\text {direct }}}{\partial Q}+M R\left(s_{2}^{\text {direct }}\right)\left(1-\frac{\partial s_{1}^{\text {direct }}}{\partial Q}\right) \\
& -M R\left(s_{1}^{\text {im }}\right) \frac{\partial s_{1}^{i m}}{\partial Q}-M R\left(s_{2}^{\text {im }}\right)\left(1-\frac{\partial s_{1}^{i m}}{\partial Q}\right) \\
& +\varepsilon_{1}\left(\frac{\partial s_{1}^{\text {direct }}}{\partial Q}-\frac{\partial s_{1}^{\text {im }}}{\partial Q}\right) .
\end{aligned}
$$

Notice that without any ambiguity we can write $\left(1-\frac{\partial s_{1}^{j}}{\partial Q}\right)=\frac{\partial s_{2}^{j}}{\partial Q}, j=$ im, direct.

The following lemma shows that direct exports are more sensitive to demand shocks than trade intermediated by an import intermediary.

Lemma 5 Given inventory level $Q$ and the resolved demand shock $\varepsilon_{1}$ in period 1 , if $\varepsilon_{1}<0$, then $s_{1}^{\text {direct }}<s_{1}^{\text {im }}$ and $s_{2}^{\text {direct }}>s_{2}^{\text {im }}$; if $\varepsilon_{1}>0$, then $s_{1}^{\text {direct }}>s_{1}^{\text {im }}$ and $s_{2}^{\text {direct }}<s_{2}^{\text {im }}$, where $s_{1}^{\text {direct }}+s_{2}^{\text {direct }}=s_{1}^{i m}+s_{2}^{\text {im }}=Q$.

Proof: Using $s_{2}^{i m}=Q-s_{1}^{i m}$ and $s_{2}^{\text {direct }}=Q-s_{1}^{\text {direct }}$, we can rewrite (28) as

$$
p\left(s_{1}^{i m}\right)+s_{1}^{i m} p^{\prime}\left(s_{1}^{i m}\right)+\varepsilon_{1}=p\left(s_{2}^{i m}\right)+s_{2}^{i m} p^{\prime}\left(s_{2}^{i m}\right),
$$

and

$$
p\left(s_{1}^{\text {direct }}\right)+\varepsilon_{1}=p\left(s_{2}^{\text {direct }}\right) .
$$

Then

$p\left(s_{1}^{i m}\right)-p\left(s_{1}^{\text {direct }}\right)=p\left(s_{2}^{i m}\right)+s_{2}^{i m} p^{\prime}\left(s_{2}^{i m}\right)-s_{1}^{i m} p^{\prime}\left(s_{1}^{i m}\right)-p\left(s_{2}^{\text {direct }}\right) \doteq B$. 
If $\varepsilon_{1}<0$, then clearly $\left\{s_{1}^{\text {direct }}, s_{1}^{\text {im }}\right\}<\frac{1}{2} Q<\left\{s_{2}^{\text {direct }}, s_{2}^{\text {im }}\right\}$. Suppose, for the sake of contradiction, that $s_{1}^{\text {im }}<s_{1}^{\text {direct }}$, then $B>0$ and $s_{2}^{\text {direct }}<s_{2}^{\text {im }}$. But notice

$$
\begin{aligned}
B & <p\left(s_{2}^{\text {direct }}\right)+s_{2}^{\text {direct }} p^{\prime}\left(s_{2}^{\text {direct }}\right)-s_{1}^{\text {im }} p^{\prime}\left(s_{1}^{\text {im }}\right)-p\left(s_{2}^{\text {direct }}\right) \\
& =s_{2}^{\text {direct }} p^{\prime}\left(s_{2}^{\text {direct }}\right)-s_{1}^{\text {im }} p^{\prime}\left(s_{1}^{\text {im }}\right) \\
& <0
\end{aligned}
$$

where the first inequality follows from $M R^{\prime}(s)<0$ and $s_{2}^{\text {direct }}<s_{2}^{\text {im }}$; the second inequality follows from $p^{\prime}+s p^{\prime \prime}<0$ and $s_{2}^{\text {direct }}>s_{1}^{\text {im }}$. This means there is a contradiction, and $s_{1}^{\text {direct }}<s_{1}^{\text {im }}$.

If $\varepsilon_{1}>0$, we have $\left\{s_{1}^{\text {direct }}, s_{1}^{\text {im }}\right\}>\frac{1}{2} Q>\left\{s_{2}^{\text {direct }}, s_{2}^{\text {im }}\right\}$. Suppose, for the sake of contradiction, that $s_{1}^{\text {im }}>s_{1}^{\text {direct }}$, then $B<0$ and $s_{2}^{\text {direct }}>s_{2}^{\text {im }}$. But

$$
\begin{aligned}
B & >p\left(s_{2}^{\text {direct }}\right)+s_{2}^{\text {direct }} p^{\prime}\left(s_{2}^{\text {direct }}\right)-s_{1}^{\text {im }} p^{\prime}\left(s_{1}^{\text {im }}\right)-p\left(s_{2}^{\text {direct }}\right) \\
& =s_{2}^{\text {direct }} p^{\prime}\left(s_{2}^{\text {direct }}\right)-s_{1}^{\text {im }} p^{\prime}\left(s_{1}^{\text {im }}\right) \\
& >0 .
\end{aligned}
$$

Hence there is a contradiction, and $s_{1}^{\text {direct }}>s_{1}^{i m}$.

This lemma is used to prove the following result:

Lemma $6 M R\left(s_{1}^{\text {direct }}\right) \frac{\partial s_{1}^{\text {direct }}}{\partial Q}+M R\left(s_{2}^{\text {direct }}\right) \frac{\partial s_{2}^{\text {direct }}}{\partial Q} \leq M R\left(s_{1}^{\text {im }}\right) \frac{\partial s_{1}^{\text {direct }}}{\partial Q}+$ $M R\left(s_{2}^{i m}\right) \frac{\partial s_{2}^{\text {direct }}}{\partial Q}, \forall \varepsilon_{1}$

Proof: Let $s_{L}^{\text {direct }}=\min \left\{s_{1}^{\text {direct }}, s_{2}^{\text {direct }}\right\}$, and $s_{H}^{\text {direct }}=\max \left\{s_{1}^{\text {direct }}, s_{2}^{\text {direct }}\right\}$. We may construct a function $\Gamma(x)$ with domain $x \in[0, \bar{x}]$, where $\bar{x} \doteq$ $\frac{1}{2} Q-s_{L}^{\text {direct }}=s_{H}^{\text {direct }}-\frac{1}{2} Q$, such that

$$
\begin{aligned}
\Gamma(x)= & M R\left(\frac{1}{2} Q-x\right) \frac{\partial s_{L}^{\text {direct }}}{\partial Q}+M R\left(\frac{1}{2} Q+x\right) \frac{\partial s_{H}^{\text {direct }}}{\partial Q} \\
= & M R\left(\frac{1}{2} Q-x\right) \frac{p^{\prime}\left(s_{H}^{\text {direct }}\right)}{p^{\prime}\left(s_{L}^{\text {direct }}\right)+p^{\prime}\left(s_{H}^{\text {direct }}\right)} \\
& +M R\left(\frac{1}{2} Q+x\right) \frac{p^{\prime}\left(s_{L}^{\text {direct }}\right)}{p^{\prime}\left(s_{L}^{\text {direct }}\right)+p^{\prime}\left(s_{H}^{\text {direct }}\right)} .
\end{aligned}
$$

We want to prove $\Gamma^{\prime}(x) \leq 0$, where

$$
\begin{aligned}
\Gamma^{\prime}(x)= & M R^{\prime}\left(\frac{1}{2} Q+x\right) \frac{p^{\prime}\left(s_{L}^{\text {direct }}\right)}{p^{\prime}\left(s_{L}^{\text {direct }}\right)+p^{\prime}\left(s_{H}^{\text {direct }}\right)} \\
& -M R^{\prime}\left(\frac{1}{2} Q-x\right) \frac{p^{\prime}\left(s_{H}^{\text {direct }}\right)}{p^{\prime}\left(s_{L}^{\text {direct }}\right)+p^{\prime}\left(s_{H}^{\text {direct }}\right)} .
\end{aligned}
$$


Since $p^{\prime}(\cdot)<0$, this is equivalent to proving that

$$
M R^{\prime}\left(\frac{1}{2} Q+x\right) p^{\prime}\left(s_{L}^{\text {direct }}\right)-M R^{\prime}\left(\frac{1}{2} Q-x\right) p^{\prime}\left(s_{H}^{\text {direct }}\right) \geq 0
$$

We define $\xi(s)=-\frac{s p^{\prime \prime}(s)}{p^{\prime}(s)}$ as the elasticity of the slope of the inverse demand curve. Mathematically, $\xi(s)$ is the convexity of the inverse demand function, and $\xi^{\prime}(s) \leq 0$. Then,

$$
\begin{aligned}
& M R^{\prime}\left(\frac{1}{2} Q+x\right) p^{\prime}\left(s_{L}^{\text {direct }}\right)-M R^{\prime}\left(\frac{1}{2} Q-x\right) p^{\prime}\left(s_{H}^{\text {direct }}\right) \\
\geq & M R^{\prime}\left(\frac{1}{2} Q+\bar{x}\right) p^{\prime}\left(s_{L}^{\text {direct }}\right)-M R^{\prime}\left(\frac{1}{2} Q-\bar{x}\right) p^{\prime}\left(s_{H}^{\text {direct }}\right) \\
= & M R^{\prime}\left(\frac{1}{2} Q+s_{H}^{\text {direct }}-\frac{1}{2} Q\right) p^{\prime}\left(s_{L}^{\text {direct }}\right) \\
& -M R^{\prime}\left(\frac{1}{2} Q-\frac{1}{2} Q+s_{L}^{\text {direct }}\right) p^{\prime}\left(s_{H}^{\text {direct }}\right) \\
= & M R^{\prime}\left(s_{H}^{\text {direct }}\right) p^{\prime}\left(s_{L}^{\text {direct }}\right)-M R^{\prime}\left(s_{L}^{\text {direct }}\right) p^{\prime}\left(s_{H}^{\text {direct }}\right) \\
= & p^{\prime}\left(s_{L}^{\text {direct }}\right) p^{\prime}\left(s_{H}^{\text {direct }}\right)\left[\frac{M R^{\prime}\left(s_{H}^{\text {direct }}\right)}{p^{\prime}\left(s_{H}^{\text {direct }}\right)}-\frac{M R^{\prime}\left(s_{L}^{\text {direct }}\right)}{p^{\prime}\left(s_{L}^{\text {direct }}\right)}\right] \\
= & p^{\prime}\left(s_{L}^{\text {direct }}\right) p^{\prime}\left(s_{H}^{\text {direct }}\right)\left[2-\xi\left(s_{H}^{\text {direct }}\right)-2+\xi\left(s_{L}^{\text {direct }}\right)\right] \\
= & p^{\prime}\left(s_{L}^{\text {direct }}\right) p^{\prime}\left(s_{H}^{\text {direct }}\right)\left[\xi\left(s_{L}^{\text {direct }}\right)-\xi\left(s_{H}^{\text {direct }}\right)\right] \\
\geq & 0
\end{aligned}
$$

The first inequality comes from $M R^{\prime \prime}(s) \geq 0$ and $p^{\prime}(s)<0$; the second inequality comes from $\xi^{\prime}(s) \leq 0$, which holds since by Assumption (A2) we have $2 p^{\prime \prime}(s)+s p^{\prime \prime \prime}(s) \leq \frac{s\left[p^{\prime \prime}(s)\right]^{2}}{p^{\prime}(s)}+p^{\prime \prime}(s)$. This proves that $\Gamma^{\prime}(x) \leq 0$.

Define $x^{\text {direct }} \doteq\left|s_{1}^{\text {direct }}-\frac{1}{2} Q\right|=\left|s_{2}^{\text {direct }}-\frac{1}{2} Q\right|$, and $x^{\text {im }} \doteq\left|s_{1}^{\text {im }}-\frac{1}{2} Q\right|=$ $\left|s_{2}^{i m}-\frac{1}{2} Q\right|$. From Lemma 5 we know $x^{\text {direct }}>x^{i m} \cdot{ }^{26}$ Since $\Gamma^{\prime}(x) \leq 0$ it follows that $\Gamma\left(x^{\text {direct }}\right) \leq \Gamma\left(x^{i m}\right)$. This implies that $M R\left(s_{1}^{\text {direct }}\right) \frac{\partial s_{1}^{\text {direct }}}{\partial Q}+$ $M R\left(s_{2}^{\text {direct }}\right) \frac{\partial s_{2}^{\text {direct }}}{\partial Q} \leq M R\left(s_{1}^{\text {im }}\right) \frac{\partial s_{1}^{\text {direct }}}{\partial Q}+M R\left(s_{2}^{\text {im }}\right) \frac{\partial s_{2}^{\text {direct }}}{\partial Q}$.

\footnotetext{
${ }^{26}$ If $\varepsilon_{1}<0$, from Lemma (5), $s_{1}^{\text {direct }}<s_{1}^{\text {im }}<\frac{1}{2} Q<s_{2}^{\text {im }}<s_{2}^{\text {direct }}$, then $x^{\text {direct }}=$ $\frac{1}{2} Q-s_{1}^{\text {direct }}=s_{2}^{\text {direct }}-\frac{1}{2} Q, x^{\text {im }}=\frac{1}{2} Q-s_{1}^{\text {im }}=s_{2}^{\text {im }}-\frac{1}{2} Q$. The case of $\varepsilon_{1}>0$ is similar.
} 
Applying Lemma 6, we know that

$$
\begin{aligned}
\Delta \leq & M R\left(s_{1}^{i m}\right) \frac{\partial s_{1}^{\text {direct }}}{\partial Q}+M R\left(s_{2}^{\text {im }}\right)\left(1-\frac{\partial s_{1}^{\text {direct }}}{\partial Q}\right) \\
& -M R\left(s_{1}^{\text {im }}\right) \frac{\partial s_{1}^{\text {im }}}{\partial Q}-M R\left(s_{2}^{\text {im }}\right)\left(1-\frac{\partial s_{1}^{i m}}{\partial Q}\right)+\varepsilon_{1}\left(\frac{\partial s_{1}^{\text {direct }}}{\partial Q}-\frac{\partial s_{1}^{\text {im }}}{\partial Q}\right) \\
= & M R\left(s_{1}^{\text {im }}\right)\left(\frac{\partial s_{1}^{\text {direct }}}{\partial Q}-\frac{\partial s_{1}^{\text {im }}}{\partial Q}\right)+M R\left(s_{2}^{\text {im }}\right)\left(\frac{\partial s_{1}^{\text {im }}}{\partial Q}-\frac{\partial s_{1}^{\text {direct }}}{\partial Q}\right) \\
& +\varepsilon_{1}\left(\frac{\partial s_{1}^{\text {direct }}}{\partial Q}-\frac{\partial s_{1}^{i m}}{\partial Q}\right) \\
= & {\left[M R\left(s_{1}^{\text {im }}\right)-M R\left(s_{2}^{\text {im }}\right)\right]\left(\frac{\partial s_{1}^{\text {direct }}}{\partial Q}-\frac{\partial s_{1}^{\text {im }}}{\partial Q}\right)+\varepsilon_{1}\left(\frac{\partial s_{1}^{\text {direct }}}{\partial Q}-\frac{\partial s_{1}^{\text {im }}}{\partial Q}\right) } \\
= & -\varepsilon_{1}\left(\frac{\partial s_{1}^{\text {direct }}}{\partial Q}-\frac{\partial s_{1}^{i m}}{\partial Q}\right)+\varepsilon_{1}\left(\frac{\partial s_{1}^{\text {direct }}}{\partial Q}-\frac{\partial s_{1}^{\text {im }}}{\partial Q}\right) \\
= & 0,
\end{aligned}
$$

where we have used that fact that (28) implies $M R\left(s_{1}^{i m}\right)-M R\left(s_{2}^{i m}\right)=-\varepsilon_{1}$.

$\Delta \leq 0$ means that, given an inventory level $Q$, the marginal total revenue is always smaller when the manufacturer exports directly for any given $\varepsilon_{1}$. Thus we know that at the beginning of period 1 before demand is revealed, the expected total marginal revenue is smaller in the case of direct exports than in the case where trade is intermediated by an import intermediary. Since the manufacturer's marginal cost is the same in both cases, but expected total marginal revenue is greater in the latter case, it follows that $Q^{\text {direct }} \leq Q^{\text {im }} \cdot{ }^{27}$

Finally we want to show that if $Q^{\text {direct }}=Q^{i m}=Q$, then consumer prices are higher in the case of direct exports, so that the welfare result goes through. Denote by $\Sigma P^{j}=p\left(s_{1}^{j}\right)+\varepsilon_{1}+p\left(s_{2}^{j}\right), j=$ direct, $i m$ the sum of first period price and expected second period price, given the realized $\varepsilon_{1}$ in period 1. Then

$$
\Sigma P^{\text {direct }}-\Sigma P^{i m}=\left[p\left(s_{1}^{\text {direct }}\right)+p\left(s_{2}^{\text {direct }}\right)\right]-\left[p\left(s_{1}^{i m}\right)+p\left(s_{2}^{i m}\right)\right] .
$$

Consider a function

$$
\Phi(x)=p\left(\frac{1}{2} Q+x\right)+p\left(\frac{1}{2} Q-x\right) .
$$

From Lemma 5 we know that $x^{\text {direct }}>x^{\text {im }}$, where $x^{\text {direct }}=\frac{1}{2} Q-s_{L}^{\text {direct }}=$ $s_{H}^{\text {direct }}-\frac{1}{2} Q$ and $x^{i m}=\frac{1}{2} Q-s_{L}^{i m}=s_{H}^{i m}-\frac{1}{2} Q$. Furthermore $\Phi^{\prime}(x)=$ $p^{\prime}\left(\frac{1}{2} Q+x\right)-p^{\prime}\left(\frac{1}{2} Q-x\right)$, and from $p^{\prime \prime}(s) \geq 0$ we know $\Phi^{\prime}(x) \geq 0$. This yields $\Phi\left(x^{\text {direct }}\right) \geq \Phi\left(x^{i m}\right)$, which means $\Sigma P^{\text {direct }}-\Sigma P^{i m} \geq 0$.

\footnotetext{
${ }^{27}$ Here we can easily check that the total revenue function is concave.
} 
Combining the result that $Q^{\text {direct }} \leq Q^{\text {im }}$ with the result that if $Q^{\text {direct }}=$ $Q^{i m}$ then $\Sigma P^{\text {direct }}-\Sigma P^{i m} \geq 0$ completes the proof that import wholesalers increase social welfare relative to direct exports if trade is lumpy.

\section{References}

[1] Ahn, JaeBin, Amit K. Khandelwal and Shag-Jin Wei, 2011. The Role of Intermediaries in Facilitating Trade, Journal of International Economics 84, 73-85.

[2] Akerman, Anders, 2011. A Theory on the Role of Wholesalers in International Trade, Stockholm University.

[3] Alessandria, George, Joseph Kaboski and Virgiliu Midrigan, 2014. 'Trade Wedges, Inventories, and International Business Cycles', Journal of Monetary Economics, forthcoming (and NBER WP 18191).

[4] Alessandria, George, Joseph P. Kaboski, and Virgiliu Midrigan. 2011. "US Trade and Inventory Dynamics," American Economic Review 101(3), 303-07.

[5] Alessandria, George, Joseph Kaboski and Virgiliu Midrigan, 2010a, 'Inventories, Lumpy Trade and Large Devaluations', American Economic Review 100, 5, 2304-39.

[6] Alessandria, George, Joseph Kaboski, and Virgiliu Midrigan, 2010b. "The Great Trade Collapse of 2008 - 09: An Inventory Adjustment?" IMF Economic Review 58(2): 254-94.

[7] Allon G. and van Mieghem J. A., 2010. Global Dual Sourcing: Tailored Base-Surge Allocation to Near- and Offshore Production, Management Science 56, 110-124.

[8] Altomonte, Carlo; Filippo Di Mauro; Gianmarco Ottaviano; Armando Rungi and Vincent Vicard, 2013. Global Value Chains During the Great Trade Collapse: A Bullwhip Effect?, in S. Beugelsdijk, S. Brakman, H. van Ees and H. Garretsen (eds.), Firms in the International Economy, CESifo Seminar Series, MIT Press, Cambridge (Mass.).

[9] Antras, Paul and Antoine Costinot, 2011. Intermediated Trade, Quarterly Journal of Economics 126, 3, 1319-74.

[10] Automotive Logistics, 2014. 'Tibbett Logistics increases auto footprint in Romania', September 22, http://www.automotivelogisticsmagazine.com/news/tibbett-logisticsincreases-auto-footprint-in-romania 
[11] Baldwin, Richard, 2012. Global supply chains: Why they emerged, why they matter, and where they are going, CEPR Discussion Paper 9103.

[12] Baldwin, Richard and Anthony Venables, 2013. Spiders and Snakes: Offshoring and Agglomeration in the Global Economy, Journal of International Economics 90, 245-54.

[13] Belavina, Elena and Karam Girotra, 2012a. The Relational Advantages of Intermediation, Management Science 58, 9, 1614-31.

[14] Belavina, Elena and Karam Girotra, 2012b. The Benefits of Decentralized Decision-making in Supply Chains, INSEAD Wp 79.

[15] Bernard, Andrew, Bradford Jensen, Stephen Redding and Peter Schott, 2010. Wholesalers and Retailers in US Trade, American Economic Review Papers and Proceedings 100, 408-13. Long version: NBER $\mathrm{WP} \# 15660$.

[16] Bernard, Andrew, Marco Grazzi and Chiara Tomasi, 2011. Intermediaries in International Trade: Direct versus Indirect Modes of Export, NBER WP 17711.

[17] Biyalogorsky, Eyal and Oded Koenigsberg, 2010. 'Ownership Coordination in a Channel: Incentives, Returns, and Negotiations,' Quantitative Marketing and Economics 8, 4, 461-490.

[18] Blum, Bernardo, Sebastian Claro and Ignatius Horstmann, 2012. Intermediation and the Nature of Trade Costs: Theory and Evidence, University of Toronto, mimeo, March.

[19] Bonney, Joseph and Peter Leach, 2010. 'Slow Boat from China,' Journal of Commerce, February 1, Issue 5, 10-14.

[20] Cachon, Gerard, 2004, The Allocation of Supply Risk in a Supply Chain: Push, Pull and Advance-Purchase Discount Contracts, Management Science 50, 2, 222-38.

[21] Chen, Lucy Gongtao and Srinagesh Gavirneni, 2010. Using Scheduled Ordering to Improve the Performance of Distribution Supply Chains, Management Science 56, 9, 1615-32.

[22] Costinot, A., J. Vogel and S. Wang, 2013. An Elementary Theory of Global Supply Chains, Review of Economic Studies 80, 1, 109-144.

[23] Cristea, Anca, David Hummels, Laura Puzello, and Misak Avetisyan, 2013. 'Trade and the Greenhouse Gas Emissions form International Freight Transport,' Journal of Environmental Economics and Management $65,1,153-73$. 
[24] Crozet, Matthieu, Guy Lalanne, and Sandra Poncet, 2013. Wholesalers in International Trade, European Economic Review 58: 1-17.

[25] Evans, Carolyn and James Harrigan, 2005. Distance, Time, and Specialization: Lean Retailing in General Equilibrium, American Economic Review 95, 1, 292-313.

[26] Fally, Thibault and Russell Hillberry, 2014. A Coasian Model of International Production Chains, UC-Berkeley, mimeo.

[27] Feenstra, Robert and Gordon Hanson, 2004. Intermediaries in Entreport Trade: Hong-Kong re-exports of Chinese Goods, Journal of Economics and Management Strategy 13, 3-35.

[28] Felbermayr, Gabriel, and Benjamin Jung, 2011. Trade Intermediation and the Organization of Exporters, Review of International Economics 19(4), 634-48.

[29] Forrester, Jay W., 1961. Industrial Dynamics, MIT Press and John Wiley \& Sons, New York.

[30] Hall, George and John Rust, 2000. 'An Empirical Model of Inventory Investment by Durable Commodity Intermediaries', Carnegie-Rochester Conference Series on Public Policy 52, 1, 171-214.

[31] Hornok, Cecilia and Miklos Koren, 2014. Per Shipment Costs and the Lumpiness of International Trade, Review of Economics and Statistics, forthcoming.

[32] Hummels, David and Georg Schaur, 2013. 'Time as a Trade Barrier', American Economic Review 103(7), 2935-59.

[33] Industry Canada, 2008. State of Logistics: The Canadian Report 2008, Ottawa.

[34] Jain, Nitish, Karan Girotra and Serguei Netessine, 2014. Managing Global Sourcing: Inventory Performance, Management Science 60, 5, $1202-22$.

[35] Johnson, Eric, 2001. 'Learning From Toys: Lessons in Managing Supply Chain Risk from the Toy Industry," California Management Review 43, $3,106-24$.

[36] Krautheim, Sebastian, 2013. 'Export-Supporting FDI', Canadian Journal of Economics 45(4), 1431-35.

[37] Kropf, Andreas and Philip Sauré, 2013. Fixed Costs per Shipment, Journal of International Economics 92, 166-84. 
[38] Lavigne, Grace, 2014. Retailers expect continued growth in US containerized imports, JOC.com, July 10. http://www.joc.com/portnews/us-ports/retailers-expect-continued-growth-containerizedimports_20140710.html

[39] PRWeb, 2012. 'Ankaka Wholesale Announces New Plans for Easy Wholesale Dropshipping Anywhere', Press release, Nov 26, http://www.prweb.com/releases/2012/11/prweb10167398.htm

[40] PRWeb, 2006. 'Consumer Electronics Importers Going Straight To The Source In China at Chinavasion.com', August 23, http://www.prweb.com/releases/china/wholesale/prweb427625.htm

[41] Raff, Horst and Nicolas Schmitt, 2007. Why Parallel Trade May Raise Producers' Profits, Journal of International Economics 71, 434-447.

[42] Randall, Taylor, Netessine, Sergei and Nils Rudi, 2006, An Empirical Examination of the Decision to Invest in Fulfillment Capabilities: A Study of Internet Retailers, Management Science 52, 4, 567-80.

[43] Schröder, Philipp, Harald Trabold and Parvati Trübswetter, 2005. Intermediation in Foreign Trade: When Do Exporters Rely on Intermediaries?, Applied Economics Quarterly 51, 3, 267-88.

[44] Spulber, Daniel, 1999, Market Microstructure: Intermediaries and the Theory of the Firm, Cambridge University Press.

[45] World Bank, 2014. Logistics Performance Index, Report, Washington D.C. 